\title{
Macroprudential Policy in the Presence of External Risks*
}

\author{
Ricardo Reyes-Heroles ${ }^{\dagger} \quad$ Gabriel Tenorio ${ }^{\ddagger}$
}

February 2019

\begin{abstract}
We characterize optimal macroprudential policy in response to external risks - shocks to the level and volatility of world interest rates - in a small open economy subject to financial crises. Low and stable world interest rates reinforce overborrowing arising from a pecuniary externality generated by collateral constraints that depend on asset prices. We show that this mechanism leads to greater exposure to crises typically accompanied by abrupt increases in interest rates and a persistent rise in their volatility, as commonly observed for crises in emerging market economies. A tax on international borrowing implementing the optimal policy depends on two factors, the incidence and severity of future crises. We show that the interaction of these factors implies that the tax responds to external risks even though equilibrium allocations do not, and that it does so non-monotonically with respect to the direction of external shocks - higher macroprudential taxes are not always the optimal policy in response to an increase in external risks-.
\end{abstract}

JEL classification: E6, F3, F4

Keywords: Macroprudential policy, time-varying volatility, financial crises, sudden stops, external interest rates.

${ }^{*}$ We thank Mark Aguiar, Adrien Auclert, Gianluca Benigno, Javier Bianchi, Jesús Fernández-Villaverde, Nils Gornemannn, Oleg Itskhoki, Nobu Kiyotaki, Enrique Mendoza, Gaston Navarro, Andrea Raffo and Chris Sims as well as participants at numerous seminars for helpful comments. Special thanks to Sebastian Di Tella, Victoria Nuguer and Andrei Zlate for very useful discussions. Both authors gratefully acknowledge financial support from the International Economics Section at Princeton University. Gabriel Tenorio thanks the Griswold Center for Economic Policy Studies for its financial support. The views in this paper are solely the responsibility of the authors and should not be interpreted as reflecting the views of the Board of Governors of the Federal Reserve System or of any other person associated with the Federal Reserve System or Bank of America Merrill Lynch.

${ }^{\dagger}$ Division of International Finance, Federal Reserve Board, 20th and C Streets N.W., Washington, D.C. 20551, U.S.A. E-mail: ricardo.m.reyes-heroles@frb.gov

${ }^{\ddagger}$ Research Division, Bank of America Merrill Lynch, One Bryant Park, New York, N.Y. 10036, U.S.A. E-mail: gabriel.tenorio@baml.com 


\section{Introduction}

Global factors affect countries' economic activity independently of their specific macroeconomic conditions. The 2008 Global Financial Crisis not only provided evidence for these risks, but also prompted the possibility of using macroprudential policies to reduce the size and frequency of crises associated with these forces. ${ }^{1,2}$ However, despite the evident risks associated with external factors leading to volatile asset prices and capital flows, the implications of such risks for the design and implementation of optimal macroprudential policy have not been cerefully studied.

This paper characterizes optimal macroprudential policy in response to external risks in the form of shocks to the level and volatility of world interest rates in a model of financial crises. ${ }^{3}$ We consider a quantitative framework consisting of a small open economy facing an external borrowing limit that depends on the value of a domestic non-tradable asset. External risks arise from two sources: shocks to the level of interest rates, and the existence of multiple stochastic regimes in the variance of interest rates at which the economy borrows. We show that, in the model, low and stable world interest rates reinforce "overborrowing" and lead to greater exposure to financial crises typically accompanied by abrupt increases in interest rates and a persistent rise in external interest rate volatility. These predictions are in line with existing empirical evidence for emerging market economies (EMEs). We solve for the optimal policy and show that the size of a macroprudential tax on international borrowing that implements the policy depends on the incidence - reflecting the likelihood - and the severity - reflecting the magnitude of a pecuniary externality — of potential future crises. ${ }^{4}$ We show that volatility shocks affect the economy mainly through their effects on the pecuniary externality: Optimal taxes are contingent on both the level and volatility of interest rates even though optimal decisions in the competitive equilibrium do not respond significantly to changes in volatility regimes. More strikingly, we also show that the size of the optimal tax is non-monotonic with respect to both types of shocks. For instance, contrary to conventional wisdom, for certain borrowing levels

\footnotetext{
${ }^{1}$ The relevance of global factors for developing countries has been known since Calvo et al. (1996). Rey (2015) and Miranda-Agrippino and Rey (2015) provide evidence of the existence a global financial cycle and argue in favor of macroprudential policies in response to this factor. Mackowiak (2007), Chang and Fernández (2013), and Ahmed and Zlate (2013) assess and highlight the relevance of global risks. Johri et al. (2015) highlight the role of global uncertainty in shaping default decisions.

${ }^{2}$ This possibility has motivated the development of a framework to analyze the benefits of macroprudential policies, establishing grounds for the optimal use of these instruments. See, for example Lorenzoni (2008), Bianchi (2011) and Bianchi and Mendoza (2018) and Schmitt-Grohé and Uribe (2017). Korinek and Mendoza (2013) provide a survey of recent contributions.

${ }^{3}$ We follow previous literature by Uribe and Yue (2006), Neumeyer and Perri (2005), and Fernández-Villaverde et al. (2011) and refer to shocks to world interest rates as external because we consider them to be driven by factors other than countries' fundamentals.

${ }^{4}$ We will refer to these terms throughout the paper and will define each precisely after we describe the model.
} 
it is optimal to reduce taxes on international borrowing when interest rate volatility rises. ${ }^{5}$ We are not aware of any existing results on the implications of volatility for optimal policy. Hence, we believe this paper provides the first set of theoretically grounded results regarding the optimal use and, most importantly, the implementation of macroprudential policy in the presence of volatility shocks. ${ }^{6}$ We see these results as particularly relevant given the concerns by policymakers regarding volatility in global financial markets.

A vast literature has documented how factors independent of countries' fundamentals affect economic activity in both advanced and emerging economies. ${ }^{7}$ The literature has focused primarily on the effects on EMEs' business cycles, including the sudden stops nested within these cycles. For instance, it is a well known fact that shocks to external interest rates at which EMEs borrow have significant effects on their real economic activity and capital flows. Furthermore, studies have identified that not only the first, but also the second moment of these shocks matter. ${ }^{8}$ However, the literature on macroprudential policy based on pecuniary externalities that generate "overborrowing" (Lorenzoni, 2008) has not yet studied the design and implementation of such policies in the presence of shocks to the level and volatility of interest rates. This is particularly relevant given that interest rate shocks have important implications for the forward-looking component of asset prices. ${ }^{9,10}$ In this paper we fill this gap in the literature by focusing on the effects of shocks to the level and volatility of world interest rates into a framework with asset-backed collateral constraints to study the qualitative and quantitative features of optimal macroprudential policy.

We consider an open economy model with an asset-backed collateral constraint. Households' only source of income is the payoff of a risky domestic asset whose market value limits non-

\footnotetext{
${ }^{5}$ This conventional wisdom comes from the idea that higher volatility in world interest rates directly translates into more volatile capital flows and consequent risks. The following statement provides an example: "There is now a growing recognition that the short-term nature and inherent volatility of global capital flows are problematic." (Christine Lagarde, https://www.imf.org/external/np/speeches/2016/020416.htm)

${ }^{6}$ See Fernández-Villaverde and Rubio-Ramírez (2010) for an analysis of the relevance of volatility in macroeconomics and its policy implications.

${ }^{7}$ For example, Rey (2015) considers the effects of global financial cycles, Mackowiak (2007) and Chang and Fernández (2013) focus on the effects on EMEs.

${ }^{8}$ For business cycles in general, Neumeyer and Perri (2005) and Uribe and Yue (2006) consider the effects of shocks to the level of interest rates, while Fernández-Villaverde et al. (2011) focus on the effects of shocks to their volatility. Reyes-Heroles and Tenorio (2017) focus on the effects of both kinds of shocks for sudden stops in particular. See Ahmed and Zlate (2013) for the effects on capital flows.

${ }^{9}$ The pecuniary externality is induced by a collateral constraint on international borrowing in which the collateral is valued at market prices - either the price of an asset or the real exchange rate - which themselves depend upon aggregate external indebtedness. Korinek (2011) and Korinek and Mendoza (2013) provide surveys of the literature.

${ }^{10}$ Bianchi et al. (2016) and Schmitt-Grohé and Uribe (2017) also study optimal policy when world interest rates follow a stochastic process. However, they do not incorporate stochastic volatility into their framework, which considers income as collateral rather than the value of an asset. This framework does not incorporate the forward-looking component of asset prices that are affected by shocks to interest rates.
} 
contingent riskless foreign debt. ${ }^{11}$ Our model differs from previous work in two main respects. First, we extend models of macroprudential policy with asset-backed collateral constraints by allowing the interest rate at which the economy borrows to follow a stochastic process with time-varying volatility. Our model incorporates the effects of shocks to the level and volatility of the interest rate on (i) household refinancing risks and (ii) the relationship between domestic asset prices and interest rates. Hence, these shocks have implications for the incidence and severity of financial crises - or sudden stops - that occur when households borrow up to the point where the borrowing constraint binds. Second, we provide a microfoundation of the collateral constraint based on contractual imperfections. Our microfoundation takes into account the asymmetry in open economy models with credit constraints due to the fact that the risky asset cannot be traded across borders. Even though the qualitative implications of the constraint for optimality conditions are the same as those in existing models, we show precisely how these conditions differ when the collateral constraint binds.

We characterize the model's competitive equilibrium and show how shocks to the level and volatility of external interest rates affect the pecuniary externality that leads to "overborrowing" and large financial crises. Shocks to the level and volatility of external interest rates have implications for the incidence and severity of crises in equilibrium. The incidence of crises increases in the presence of low and stable interest rates that incentivize households to borrow more, even when such rates also decrease the risks of refinancing debt and hedge against future shocks. The severity of crises is affected by how shocks to interest rates affect asset prices in equilibrium. Then, after characterizing the competitive equilibrium, we consider the problem of a social planner that internalizes the effects of borrowing on the price of the asset and compare the optimal allocations of this planner with those arising from the equilibrium. The planner internalizes the effects of borrowing on asset prices and on the borrowing constraint but cannot choose asset prices directly or commit to future policies. ${ }^{12}$ To prevent "overborrowing," the planner takes into account the interaction between the incidence and the severity of future crises and reduces these two factors by keeping asset prices depressed relative to those in the competitive equilibrium.

We solve the model numerically using global methods and analyze the response of the competitive equilibrium's policy functions to external shocks as well as the dynamics generated by the model around crisis episodes. ${ }^{13}$ We first show that the response of the competitive equilibrium's policy functions to shocks to levels of interest rates is numerically sizable, but

\footnotetext{
${ }^{11}$ Our framework is closest to the models of Jeanne and Korinek (2010) and Bianchi and Mendoza (2018).

${ }^{12}$ However, the planner must act according to asset prices being consistent with equilibrium conditions.

${ }^{13}$ The use of global methods is critical for this type of model in order to fully characterize the nonlinearities that arise in the region where the collateral constraint binds.
} 
that such effects are not present when we analyze the response to shocks to the volatility of external interest rates. We argue that this unresponsiveness arises because the change in optimal decisions due to precautionary motives associated with volatility shocks is absorbed by changes in prices rather than in aggregate allocations. ${ }^{14}$ Then we show that the model can replicate existing empirical event analyses of financial crises in EMEs. ${ }^{15}$ Low and stable interest rates precede sudden stops that lead to a large drop in consumption and a reversal of capital flows concurrently with a persistent increase in the level and volatility of interest rates. The ability of the model to replicate the data reassures that our framework is useful to study optimal policy in the presence of shocks to external interest rates. ${ }^{16}$

In the last and main part of the paper, we provide a detailed study of the implications of external shocks for optimal policy. We show that a state-contingent tax on debt implements the planner's optimal allocations and that the size of this tax is shaped by the incidence and severity of potential future crises. Hence, we proceed to focus our analysis on the response of the entire optimal tax schedule to external shocks. ${ }^{17}$ Our initial analysis shows that the optimal tax is contingent on both types of external shocks. Even though this result was expected for the case of shocks to the level of interest rates - precisely because of our previous result showing that the equilibrium's policy function responds to these shocks - the fact that the optimal tax also responds to shocks to external volatility highlights the role of the pecuniary externality. Shocks to volatility translate into large changes in asset prices instead of allocations, whose effects on the collateral are internalized by the planner but not by households. No previous work has highlighted other shocks leading to macroprudential policy primarily through this price effect, and we see this finding as an important contribution of this paper. The second result of this analysis is that the level of the tax on capital flows is non-monotonic with respect to external shocks. In other words, the tax schedule does not shift monotonically for different magnitudes of external shocks. For instance, it is optimal to increase the tax on international borrowing when interest rates decrease, but not if the level of debt is very high given a high interest rate. ${ }^{18}$ This is a novel insight that we also see as an important contribution of this paper. One corollary that follows from this result should be underscored: Simple intuition would

\footnotetext{
${ }^{14}$ Our model does not incorporate other mechanisms that could amplify the effects of external volatility shocks. For instance, Fernández-Villaverde et al. (2011) emphasize the role of investment, which we do not incorporate, but discuss in detail later in the paper. We consider the simplicity of our model an advantage to clarify the central mechanism underlying the effect of external volatility on optimal taxes on capital flows. Hence, our results could be interpreted as a lower bound on the responsiveness of optimal policy to external shocks.

${ }^{15}$ We do this by simulating the model and analyzing the dynamics it generates endogenously around typical financial crises given our estimated stochastic process for shocks.

${ }^{16}$ Reyes-Heroles and Tenorio (2017) provide an empirical account of the evolution of interest rates around sudden stops for a large sample of EMEs.

${ }^{17}$ By the tax schedule we refer to the tax as a function of current debt given a profile of exogenous shocks.

${ }^{18}$ This statement will be made clearer in subsection 3.3.2 where the detailed analysis is provided.
} 
suggest that higher volatility should lead to higher taxes because more volatile capital flows increase the probability of a binding collateral constraint. However, as we carefully explain in this paper, this intuition is flawed because it does not take into account the effects of external shocks on households' precautionary motives and asset prices, and how their interaction affects the incidence and severity of potential future crises. Thus, in the last section of the paper, we provide a decomposition of the optimal tax that provides a detailed explanation of the main factors driving the implementation of optimal policy: the incidence and severity of potential future crises, and the interaction between these two.

This paper is related to two strands of the literature in international macroeconomics. First, this paper contributes to the recent literature on optimal macroprudential policy summarized in detail by Korinek and Mendoza (2013). The pecuniary externality mechanism leading to "overborrowing" is emphasized in Lorenzoni (2008), Jeanne and Korinek (2010), Bianchi (2011), Bianchi and Mendoza (2018), and Schmitt-Grohé and Uribe (2017). ${ }^{19}$ We build on the framework of Jeanne and Korinek (2010) but focus on solving for time-consistent optimal macroprudential policies, as do Bianchi and Mendoza (2018), and allow the interest rate at which the economy borrows to follow a stochastic process with time-varying volatility.

The second strand of literature to which this paper is closely related studies the effects on EMEs of shocks to the interest rate at which they borrow. ${ }^{20}$ Uribe and Yue (2006) and Neumeyer and Perri (2005) show that shocks to world interest rates are an important driver of EMEs' business cycles. Fernández-Villaverde et al. (2011) show that not only the first, but also the second moment of the shocks to interest rates have implications for real economic activity in EMEs. Reyes-Heroles and Tenorio (2017) focus on sudden stops and document the empirical association between these episodes and external interest rate volatility for a large sample of EMEs. Two of their main findings are that (i) sudden stops are preceded by periods of below-normal interest rates, which rise when a sudden stop occurs and revert to their normal levels in the following years; and that (ii) sudden stops follow periods of low interest rate volatility that increases sharply at the beginning of the sudden stop and remains persistently high for multiple periods.

The rest of the paper is organized as follows. In Section 2 we introduce the theoretical model

\footnotetext{
${ }^{19}$ The literature has focused on two different aspects of optimal policy, either its "prudential" features, in the sense that policy is undertaken ex ante in order to reduce the probability of a crisis, as we do in this paper, or its ex post characteristics, after the crisis has occurred. Benigno et al. (2011) and Benigno et al. (2013a) focus on the ex post policies. Jeanne and Korinek (2013) and Benigno et al. (2013b) consider the use of both ex ante as well as ex post policies in order to mitigate the risks associated with capital flows.

${ }^{20}$ Multiple studies document the independence of interest rates from countries' fundamentals. See Rey (2015) and Miranda-Agrippino and Rey (2015) for evidence on global financial cycles, and Longstaff et al. (2011) for evidence on sovereign credit risk. Carrière-Swallow and Cépedes (2013) and Johri et al. (2015) focus on the cases of uncertainty and volatility respectively.
} 
of a small open economy facing domestic and external risks that are amplified by the effects of a collateral constraint. We describe the competitive equilibrium and discuss the presence of a pecuniary externality that motivates the intervention of a social planner to increase welfare in the economy. In Section 3 we present the results of our numerical exercises. We show that the dynamics of interest rates around episodes of sudden stops in the model are consistent with their empirical counterparts. Moreover, we explain how the optimal response of the planner is shaped by incidence and the severity of potential future crises. In Section 4 we conclude.

\section{A model of endogenous sudden stops with external interest rate risk}

\section{$2.1 \quad$ Framework}

Our framework is closely related to those of Jeanne and Korinek (2010) and Bianchi and Mendoza (2018). Consider an open economy inhabited by a continuum of unit measure of identical households that have preferences for streams of a consumption good, $c_{t}$, given by

$$
E_{0}=\sum_{t=0}^{\infty} \beta^{t} u\left(c_{t}\right)
$$

where $u$ is an increasing, concave, and differentiable function that satisfies the usual Inada conditions.

There is a Lucas tree that yields a stochastic flow of consumption goods of $d_{t}=d \exp \left(z_{t}\right)$ per period. The flow of goods provided by the tree can be traded period by period with the rest of the world, but the stocks of the tree can only be held by domestic households. A possible explanation is that this arrangement arises from drastic asymmetries of information between domestic managers and international investors that impede foreigners from earning profit by holding stocks of the tree. We denote by $q_{t}$ the market value of the tree at time $t$, and by $s_{t}$ the holdings of the asset chosen by the representative household.

Households have access to debt financing in international financial markets in order to smooth their consumption and fund their stock purchases. The bonds issued by households in international markets have a maturity of one period, and they pay an exogenous gross return of $R_{t}=R \exp \left(r_{t}\right)$. We let the external interest rate have a stochastic transition, but debt contracts are locally risk free: A household knows at time $t$ the interest rate that it must pay next period for its outstanding bonds, but it does not know the interest rate that it will face next period if it decides to refinance its stock of debt. 
Following the approach by Reyes-Heroles and Tenorio (2017) to study the evolution of external interest rates around sudden stops, we allow for contemporaneous correlation and dynamic feedback between the exogenous output and interest rate processes. The random vector $\left(z_{t}, r_{t}\right)^{\prime}$ has the following VAR specification:

$$
\left(\begin{array}{c}
z_{t} \\
r_{t}
\end{array}\right)=A_{0}+A_{1}\left(\begin{array}{c}
z_{t-1} \\
r_{t-1}
\end{array}\right)+\left(\begin{array}{c}
\epsilon_{t}^{z} \\
\epsilon_{t}^{r}
\end{array}\right) .
$$

The draws of the shock vector $\left(\epsilon_{t}^{z}, \epsilon_{t}^{r}\right)^{\prime}$ are independent across time, and they have a Gaussian distribution with zero mean and a covariance matrix that has itself a stochastic evolution:

$$
\Sigma_{t}=\left(\begin{array}{cc}
\left(\sigma^{z}\right)^{2} & \rho \cdot \sigma^{z} \cdot \sigma_{t}^{r} \\
\rho \cdot \sigma^{z} \cdot \sigma_{t}^{r} & \left(\sigma_{t}^{r}\right)^{2}
\end{array}\right) .
$$

As in Reyes-Heroles and Tenorio (2017), we allow the volatility of the external interest rate to take on two values, $\sigma_{t}^{r} \in\left\{\sigma_{L}^{r}, \sigma_{H}^{r}\right\}$, with $\sigma_{H}^{r}>\sigma_{L}^{r}>0$. The switching between these regimes is governed by a first-order Markov process with transition matrix П. Introducing stochastic volatility in interest rates into models used to analyze optimal macroprudential policy is an important contribution of this paper relative to previous work.

Let us denote by $b_{t}$ the face value of bonds that are held by the households at the beginning of period $t$. Throughout the paper, we follow the convention that a positive $b_{t}$ represents savings of the households overseas, whereas negative positions represent external household debt. The time $t$ budget constraint faced by a household is

$$
c_{t}+q_{t} s_{t+1}+\frac{b_{t+1}}{R_{t}}=\left(q_{t}+d_{t}\right) s_{t}+b_{t} .
$$

The key friction in this economy is that the amount of borrowing that households can undertake is limited by the value of their asset holdings. More specifically, the market value of debt issued by a representative household at time $t,-\frac{b_{t+1}}{R_{t}}$, is constrained to be less than or equal to the value of their holdings of stocks of the tree, $q_{t}^{c} s_{t+1}$, multiplied by a constant $\kappa$ that determines how stringent the financial frictions are:

$$
-\frac{b_{t+1}}{R_{t}} \leq \kappa q_{t}^{c} s_{t+1}
$$

Notice that this collateral constraint explicitly takes into account the fact that the price used to value asset holdings as collateral at time $t, q_{t}^{c}$, is not necessarily the same as the market price, $q_{t}$. This difference arises because the risky asset cannot be traded across borders, but it is still used 
as collateral by foreign lenders. In Appendix A.1, we provide a microeconomic foundation of the collateral constraint that is based on contractual imperfections, as is common in the literature of financial frictions (for example, Kiyotaki and Moore, 1997; Bernanke et al., 1999). ${ }^{21}$ The main idea is that within each period, there is a time in which households can divert a fraction $(1-\kappa)$ of the assets previously posted as collateral, sell them off at the prevailing price $q_{t}^{c}$, and default on their outstanding loans. After default, the foreign lender is entitled to the remaining fraction $\kappa$ of collateral assets, which must be sold in the domestic market at the prevailing price $q_{t}^{c}$. In the appendix, we show that the market price of the tree and its resale value need not be the same, and we also derive the relationship that has to hold in equilibrium between them.

\subsection{Competitive equilibrium}

A competitive equilibrium is a sequence of allocations $\left\{c_{t}, b_{t+1}, s_{t+1}\right\}_{t=0}^{\infty}$ for every household and prices of the tree $\left\{q_{t}, q_{t}^{c}\right\}_{t=0}^{\infty}$ (market and collateral valuations) such that households optimize their utility subject to the budget and borrowing constraints, and the market for stocks of the tree clears. Given that all the households are identical and they only face aggregate shocks, market clearing implies that $s_{t}=1$ in every period.

We rewrite the problem of the representative household in recursive form to highlight the role of pecuniary externalities in the competitive equilibrium. The aggregate states in the household's problem are the aggregate level of savings $B$ and the current realization of the stochastic shocks, which we denote by $X \equiv\left(z, r, \sigma^{r}\right)$. The individual states of a household are its holdings of bonds $b$ and stocks of the tree $s$. We denote by $V(b, s, B, X)$ the value of a household's problem with portfolio $(b, s)$ when the aggregate states are $B$ and $X$. Households take as given a perceived law of motion for aggregate bonds, $B^{\prime}=\mathcal{B}(B, X)$, in order to form expectations on future prices. Then, the Bellman equation of the problem is

$$
V(b, s, B, X)=\max _{c, b^{\prime}, s^{\prime}} u(c)+\beta \mathbb{E}\left[V\left(b^{\prime}, s^{\prime}, B^{\prime}, X^{\prime}\right) \mid X\right]
$$

\footnotetext{
${ }^{21}$ Part of the literature that considers an asset as collateral assumes that (i) the price used to value the asset as collateral is the same as the price in domestic asset markets - that is, $q_{t}^{c}=q_{t}$ in equation (3) - and that (ii) the amount of the asset relevant in the collateral constraint is the one held at the beginning of the period, $s_{t}$, rather than at the end of the period, $s_{t+1}$. For instance, Bianchi and Mendoza (2018) show that a collateral constraint of the form $-\frac{b_{t+1}}{R_{t}} \leq \kappa q_{t} s_{t}$ can be derived as an implication of incentive-compatibility constraints on borrowers if limited enforcement prevents lenders from collecting more than a fraction $\kappa$ of the value of the assets owned by a defaulting debtor. Notice that assumption (i) overlooks the asymmetry that arises in the framework in these papers from the fact that the tree can only be held by domestic owners, but foreign lenders view it as collateral. Hence, rather than starting by assuming (i), we begin with the microfoundation described in Appendix A.1 and derive an equilibrium relationship between $q_{t}$ and $q_{t}^{c}$. Regarding assumption (ii), we consider $s_{t+1}$ as the relevant amount of the asset in the collateral constraint because this is closer to the literature on sudden stops arising from this type of collateral constraint (Mendoza, 2010; Mendoza and Smith, 2006; Korinek and Mendoza, 2013).
} 
subject to

$$
\begin{aligned}
c+\mathcal{Q}(B, X) s^{\prime}+\frac{b^{\prime}}{R(X)} & =[\mathcal{Q}(B, X)+d(X)] s+b \\
-\frac{b^{\prime}}{R(X)} & \leq \kappa \mathcal{Q}^{c}(B, X) s^{\prime} \\
B^{\prime} & =\mathcal{B}(B, X) .
\end{aligned}
$$

In the previous expression, $\mathcal{Q}(B, X)$ is the market value of the tree, and $\mathcal{Q}^{c}(B, X)$ is the value of the asset when employed as collateral. These two prices are determined in equilibrium and depend on the aggregate states of the economy. In a recursive competitive equilibrium, it must be the case that $\mathcal{B}$ is consistent with optimal individual decision rules and that $\mathcal{Q}$ and $\mathcal{Q}^{c}$ ensure the clearing of the market for stocks of the tree in the different trading cycles described in Appendix A.1.

The solution to the household's problem satisfies the following Euler equations for bonds and stocks of the tree, respectively (see Appendix B):

$$
\begin{aligned}
u^{\prime}(c(b, s, B, X)) & -\mu(b, s, B, X) \\
& =R(X) \beta \mathbb{E}\left\{u^{\prime}\left(c\left(b^{\prime}, s^{\prime}, \mathcal{B}(B, X), X^{\prime}\right)\right) \mid X\right\}, \\
\mathcal{Q}(B, X) u^{\prime}(c(b, s, B, X)) & \cdot\left(1+\frac{\kappa \mu(b, s, B, X)}{u^{\prime}(c(b, s, B, X))}\right)^{-1} \\
& =\beta \mathbb{E}\left\{u^{\prime}\left(c\left(b^{\prime}, s^{\prime}, \mathcal{B}(B, X), X^{\prime}\right)\right)\left[\mathcal{Q}\left(\mathcal{B}(B, X), X^{\prime}\right)+d\left(X^{\prime}\right)\right] \mid X\right\},
\end{aligned}
$$

where $\mu \geq 0$ is the multiplier on the borrowing constraint. ${ }^{22}$ The left-hand side of the Euler equation for bonds is the marginal cost of saving an additional unit of consumption good at time $t$ : the household loses utility $u^{\prime}\left(c_{t}\right)$ in the margin, and, if the borrowing constraint is binding, an additional unit of saving relaxes the constraint, with a shadow value of $\mu_{t}$, thus reducing the marginal cost of saving. The right-hand side represents the gains obtained by the household next period: For the additional unit saved in the margin, the household gets $R_{t}$ goods in the next period, which are valued at the expected marginal utility $\mathbb{E}_{t}\left[u^{\prime}\left(c_{t+1}\right)\right]$ and discounted by the subjective discount factor $\beta$.

Similarly, the left-hand side of the Euler equation for stocks shows the marginal cost faced

\footnotetext{
${ }^{22}$ We have expressed the solution to the household's problem in terms of the equilibrium price $\mathcal{Q}(B, X)$ only by relying on the equilibrium condition between $\mathcal{Q}^{c}(B, X)$ and $\mathcal{Q}(B, X)$. If we had assumed from the beginning that $\mathcal{Q}^{c}(B, X)=\mathcal{Q}(B, X)$, then the left-hand side of the second equation would become $\mathcal{Q}(B, X) u^{\prime}(c(b, s, B, X))\left(1-\kappa \mu(b, s, B, X) / u^{\prime}(c(b, s, B, X))\right)$. Notice that the qualitative implications of a binding collateral constraint for the second condition are the same under our microfoundation of the constraint described in Appendix A.1.
} 
by a household that is buying additional shares of the tree: For each stock, the household must pay a price of $q_{t}$, and it has a marginal utility loss of $q_{t} u^{\prime}\left(c_{t}\right)$. The factor at the end of the left-hand side is the wedge between the market price of stocks of the tree and their collateral value (see Appendix A.1). This wedge arises only when the borrowing constraint is binding, which means that the household also values the additional service that asset holdings provide by increasing borrowing opportunities. In turn, the right-hand side is the expected benefit received by the household, which is the resale value of the stock, $q_{t+1}$, and the dividend, $d_{t+1}$, as valued by the marginal utility of the household, $u^{\prime}\left(c_{t+1}\right)$, and discounted by $\beta .^{23}$

In our framework, a sudden stop in external financing arises endogenously as a consequence of the households' borrowing decisions. For high levels of leverage, if the borrowing constraint binds, households are forced to sharply reduce their debt, which is only possible through a drastic decline in consumption. This drop causes a sharp decline in asset prices, generating a pecuniary externality due to the fact that households do not internalize the effect of their decisions on prices. In turn, the value of collateral is reduced, which further tightens the borrowing constraint, and induces more deleveraging. The feedback between asset price reductions, deleveraging, and drops in consumption generates a sudden reversal of the capital flows into the country.

When the external borrowing rate is lower than the households' discount factor, the households face a fundamental trade-off between impatience and insurance (Korinek and Mendoza, 2013). They have an incentive to borrow from overseas in order to consume in advance. Nonetheless, for high levels of borrowing, a crisis is more likely to happen and, given that it is accompanied by a drastic decline in consumption, households have the incentive to save and avoid the crisis region. In the next section, we illustrate numerically the interaction between these two motives.

Changes in the level of external interest rates affect the marginal cost of borrowing as shown in the right-hand side of equation (8). Low interest rates imply low marginal costs of borrowing, equivalent to a high expected stochastic discount factor, that incentivize households to acquire more debt and increase consumption in the current period, $c_{t} \cdot{ }^{24}$ Concurrently, changes in the interest rate have implications for asset prices through its effect on the stochastic discount factor, as can be seen in equation (9), and its effect on how future dividends are discounted by households. Everything else constant, low interest rates increase current asset prices, $q_{t}$, because the present value of future dividends increases. Hence, shocks to external interest rates lead to

\footnotetext{
${ }^{23}$ Alternative specifications of the household's problem, such as Jeanne and Korinek (2010), assume that the household's borrowing is constrained by the aggregate number of stocks in the economy rather than the household's individual holdings. This assumption eliminates the effect of relaxing the borrowing constraint through an increase of the value of collateral in the Euler equation for stocks (that is, the wedge between the market and collateral values of the tree).

${ }^{24}$ Conditional on the collateral constraint not binding in the current period, $t$, the stochastic discount factor is given by $\beta \frac{u^{\prime}\left(c_{t+1}\right)}{u^{\prime}\left(c_{t}\right)}$ which in equilibrium must equal to $R_{t}^{-1}$ in expectation.
} 
more volatile capital flows and domestic asset prices. Notice that as long as changes in interest rates are somewhat persistent, these changes will also affect the likelihood of the collateral constraint binding in future periods through two effects: a direct effect on the marginal cost of debt and an indirect effect on the future value of collateral. These additional implications of changes in world interest rates also affect households' optimal decisions.

Changes in the volatility of the world interest rate while keeping them constant affect households' optimal decisions by increasing the volatility of future consumption. An increase in the volatility implies that debt becomes a worse instrument for hedging against future income shocks since it increases the risk of refinancing debt in the future. Therefore, households reduce their debt, which leads to a reduction in current consumption, $c_{t} \cdot{ }^{25}$ The change in volatility also has implications for asset prices. Households could, in principle, liquidate assets to smooth consumption, thus leading to a drop in the prices of those assets. However, if the precautionary motive by the household is strong enough, it could also lead to increased demand for assets and higher prices. Overall, shocks to the volatility of external interest rates will lead to more volatile capital flows and asset prices. In the rest of the paper we explore these mechanisms and how they shape optimal policy in detail.

The fact that shocks to the level and volatility of interest rates affect borrowing decisions and asset prices implies that these shocks have implications for the pecuniary externality and by extension for the incidence and severity of potential future crises. In the next section we provide a formal definition of the incidence and severity of crises in the context of our model and show how a planner takes these two aspects of crises into account by internalizing the pecuniary externality.

\subsection{Constrained efficient allocation}

A pecuniary externality in this economy is generated by the fact that aggregate debt determines asset prices and that these, in turn, affect the borrowing capacity of households. Individual households do not internalize the effect of their indebtedness on the borrowing capacity of all households, which results in Pareto-inefficient allocations. In this section, we study the problem of a social planner that internalizes the effect of external indebtedness on the value of collateral and, hence, on the borrowing capacity of the country. In particular, we consider a social planner that can only choose the level of aggregate debt, subject to the economy's borrowing constraint. The planner cannot directly intervene in the domestic asset markets where trading takes place between households, so it tries to affect the equilibrium value of collateral

\footnotetext{
${ }^{25}$ More volatile consumption in the future implies that $\mathbb{E}_{t} u^{\prime}\left(c_{t+1}\right)$ increases (by Jensen's inequality), which in turn implies that current consumption must decline for (8) to hold for fixed $R_{t}$.
} 
indirectly by altering the economy's borrowing decisions. We assume that the planner cannot commit to future policies, and we solve for the constrained efficient allocation implemented through time-consistent policies. ${ }^{26}$

We follow Klein et al. (2005) in laying out the social planner's problem and in finding its time-consistent solution. In particular, we restrict attention to the case in which policy rules only depend on the current state variables of the economy. This restriction implies that the policy rule of the planner is given by a simple function of the current states, $(B, X)$, that maps them into levels of aggregate bonds, $B^{\prime}=\Psi(B, X)$. In Appendix $\mathrm{C}$, we show that the problem that is being solved by the social planner can be stated as follows. Given an arbitrary future policy rule, $\Psi(B, X)$, and the associated asset pricing function, $\mathcal{Q}(B, X)$, the social planner chooses $c$ and $B^{\prime}$ that solve the following Bellman equation:

$$
W(B, X)=\max _{c, B^{\prime}}\left\{u(c)+\beta \mathbb{E}\left[W\left(B^{\prime}, X^{\prime}\right) \mid X\right]\right\}
$$

subject to

$$
\begin{aligned}
c+\frac{B^{\prime}}{R(X)} & =d(X)+B, \\
-\frac{B^{\prime}}{R(X)} & \leq \kappa \overline{\mathcal{Q}}\left(B, B^{\prime}, X\right),
\end{aligned}
$$

and the valuation of collateral is consistent with the household's trading of the stocks of the tree:

$$
\overline{\mathcal{Q}}\left(B, B^{\prime}, X\right)=\beta \mathbb{E}\left[\frac{u^{\prime}\left(d\left(X^{\prime}\right)+B^{\prime}-\frac{\Psi\left(B^{\prime}, X^{\prime}\right)}{R\left(X^{\prime}\right)}\right)\left[\mathcal{Q}\left(B^{\prime}, X^{\prime}\right)+d\left(X^{\prime}\right)\right]}{u^{\prime}\left(d(X)+B-\frac{B^{\prime}}{R(X)}\right)} \mid X\right] .
$$

In the appendix we prove that (13) is the relevant equilibrium pricing condition that the planner faces, given the microeconomic foundations that give rise to our collateral constraint. ${ }^{27,28}$

The planner's decision now internalizes the fact that increasing households' savings affects

\footnotetext{
${ }^{26}$ We follow Jeanne and Korinek (2010) and Bianchi and Mendoza (2018) in setting up the problem of the constrained social planner. Benigno et al. (2013a) point out that the solution to the constrained planner's problem differs from the Ramsey solution. This occurs because the former planner is restricted to a particular set of policy instruments.

${ }^{27}$ The planner's problem has been defined in various ways in previous studies. Jeanne and Korinek (2010) and Bianchi and Mendoza (2011) consider variations of the problem that are time-consistent by construction. For instance, Bianchi and Mendoza (2011) use the competitive equilibrium price schedule $\mathcal{Q}(B, X)$ and do not allow it to satisfy the frictionless asset pricing condition of the households. Jeanne and Korinek (2010) make assumptions on the equilibrium pricing function. The planner's problem that we consider is the same as in Bianchi and Mendoza (2018), thus allowing for the issue of time inconsistency to arise.

${ }^{28}$ Following the literature on optimal taxation under commitment, this condition has been referred to as an implementability constraint.
} 
equilibrium asset prices, which in turn alters the value of collateral in the borrowing constraint. In particular, the functions that solve the planner's problem, $c=\hat{\mathcal{C}}(B, X)$ and $B^{\prime}=\hat{\Psi}(B, X)$, must satisfy the following condition: ${ }^{29}$

$$
\begin{aligned}
u^{\prime}(\hat{\mathcal{C}}(B, X)) & -\mu(B, X)[1+\kappa R(X) \xi(B, X)] \\
& =R(X) \beta \mathbb{E}\left[u^{\prime}\left(\mathcal{C}\left(B^{\prime}, X^{\prime}\right)\right)+\kappa \mu\left(B^{\prime}, X^{\prime}\right) \psi\left(B^{\prime}, X^{\prime}\right)\right]
\end{aligned}
$$

where

$$
\psi(B, X)=\frac{\partial \overline{\mathcal{Q}}(B, \Psi(B, X), X)}{\partial B}, \quad \xi(B, X)=\frac{\partial \overline{\mathcal{Q}}(B, \Psi(B, X), X)}{\partial B^{\prime}},
$$

and $\mathcal{C}(B, X)=B+d(X)-\frac{\Psi(B, X)}{R(X)}$.

To gain some intuition on how the planner internalizes the pecuniary externality, consider the case in which the collateral constraint does not bind in the current period, $\mu(B, X)=0$. In this case, equation (14) becomes

$$
u^{\prime}(\hat{\mathcal{C}}(B, X))=R(X) \beta \mathbb{E}\left[u^{\prime}\left(\mathcal{C}\left(B^{\prime}, X^{\prime}\right)\right)-\kappa \mu\left(B^{\prime}, X^{\prime}\right) \psi\left(B^{\prime}, X^{\prime}\right)\right]
$$

The planner's intervention considers not only the possibility of a binding borrowing constraint and how tight it is through the $\mu\left(B^{\prime}, X^{\prime}\right)$ term, which formally defines the incidence of a crisis, but also the risk associated with the size of the price externality through the $\kappa \psi\left(B^{\prime}, X^{\prime}\right)$ term, which formally defines the severity of a crisis. It can be shown that when the constraint is non-binding, then (see Appendix C.1)

$$
\psi(B, X)=-\frac{u^{\prime \prime}(\mathcal{C}(B, X))}{u^{\prime}(\mathcal{C}(B, X))} \mathcal{Q}(B, X)
$$

which implies that the price externality depends on the level of asset prices and the coefficient of absolute risk aversion of the representative household. ${ }^{30}$

If the collateral constraint is binding in the current period, then $\mu(B, X)>0$, and equation (14) now includes an additional term related to a partial derivative of an unknown function, $\overline{\mathcal{Q}}$. Notice that, as pointed out by Bianchi and Mendoza (2018), this is the relevant case in which a time inconsistency problem arises for the planner. The term $\xi(B, X)=\frac{\partial \overline{\mathcal{Q}}\left(B, B^{\prime}, X\right)}{\partial B^{\prime}}$ shows that if the borrowing constraint is currently binding, the planner has an incentive to affect current asset prices by making future promises that would not be time consistent for a committed planner. ${ }^{31}$

\footnotetext{
${ }^{29}$ Klein et al. (2005) call this equation a "generalized Euler equation" because it is a functional equation of an unknown equilibrium object, in this case $\overline{\mathcal{Q}}$.

${ }^{30}$ The fact that $\psi(B, X)$ can be written in terms of unknown functions, rather than partial derivatives of unknown functions, simplifies the analysis of the functional equation.

${ }^{31}$ See Bianchi and Mendoza (2018) for a detailed explanation of the difference between a planner with and
} 
In the problem of the planner, we assumed that an arbitrary future policy rule, $\Psi(B, X)$, and its implied asset pricing function, $\mathcal{Q}(B, X)$, are taken as given. Hence, the current planner can only affect the pricing function by choosing $B^{\prime}$ and then having the future planner make decisions based on $\Psi\left(B^{\prime}, X^{\prime}\right)$, rather than committing to $B^{\prime}$ and $B^{\prime \prime}$. In Appendix C, we provide an expression for $\xi(B, X)$ that shows explicitly how it relates to having the planner take future policy rules as given.

Given the characteristics of the social planner's problem, it is straightforward to define a recursive constrained efficient allocation, conditional on arbitrary future planners' policy rules. Our definition of a constrained efficient allocation further requires that these policy rules be time consistent. In other words, we require that the policy that solves the strategic game being played by sequential planners is a fixed point, deriving in a Markov stationary policy rule. We provide further details and formal definitions of these concepts in the appendix. ${ }^{32}$

Shocks to the first and second moments of the world interest rate have important implications for the pecuniary externality. For instance, lower interest rates exacerbate "overborrowing" in the competitive equilibrium because borrowing becomes cheaper, which, in turn, increases the incidence and severity of crises. Lower volatility of interest rates also amplifies the problem of "overborrowing" by incentivizing households to acquire more debt. The planner internalizes how these shocks affect asset prices and the value of collateral, as shown in equation (14). The rest of the paper focuses on how shocks to the level and volatility of interest rates affect the planner's decisions through the incidence and severity of crises. However, first we analyze the competitive equilibirum of this economy in the presence of external shocks.

\section{The dynamics of crises and optimal policy in response to external interest rate shocks}

\subsection{Parameterization and numerical solution}

We focus here on the numerical solution of the model to provide a full analysis of the general equilibrium interactions. Hence, we proceed to choose parameter values for the model and estimate the processes of exogenous shocks. For parameter values, we either consider values in existing literature or use data to map to empirical counterparts of the model. However, we

without commitment.

${ }^{32}$ In what follows, we abstract from the possibility of multiple equilibria by making the following technical assumption: The parameters and stochastic processes of the economy are such that the equilibrium pricing function satisfies $1+\kappa R(X) \xi(B, X)>0$. See Jeanne and Korinek (2010) and Korinek and Mendoza (2013) for more details on this assumption. 
Table 1: Baseline parameterization

\begin{tabular}{lccl}
\hline \hline Parameter & & Value & Target \\
\hline Time discount & $\beta$ & 0.96 & Standard value \\
Relative risk aversion & $\gamma$ & 2 & Standard value \\
Dividends & $d$ & 1 & Normalization \\
Collateral constraint & $\kappa$ & 0.04 & Debt-to-output ratio \\
\hline \hline
\end{tabular}

remain fully aware of the simplicity of the model and its implied limitations when carrying out our exercises. We consider a utility function with constant relative risk aversion, $u(c)=\frac{c^{1-\gamma}}{1-\gamma}$.

Table 1 presents the baseline parameterization of the model for an annual time frequency. The parameters for preferences are standard in the literature of small open economies. Our choice of the relative risk aversion, $\gamma=2$, is at the lower end of the values used for emerging economies in the open economy business cycle literature. Hence, the quantitative effects of volatility on real allocations and asset prices that we show are, in principle, conservative. The mean of the dividends process, $d$, is normalized to one, so we can easily interpret the measurements of consumption, savings, and asset prices relative to the mean annual income. The parameter of the collateral constraint, $\kappa=0.04$, is chosen to match the ratio of foreign liabilities to GDP observed in a sample of emerging markets over the period from 1990 to 2011, which averaged 66.7 percent. $^{33}$ In the model, the ergodic mean of the debt-to-output ratio is 65.6 percent.

We estimate the parameters that rule the regime-switching VAR given by (1) for a group of emerging markets using the maximum likelihood approach of Reyes-Heroles and Tenorio (2017), with the data corresponding to a sample of 27 EMEs. As a useful reference, we plot in Figure 1 the evolution of the mean and 80-20 percentile ranges of the level (left panel) and volatility (right panel) of interest rates for this sample of EMEs. The data in the figure clearly shows the presence of shocks to the level and regime-switches in the volatility of interest rates. The only difference of our estimation compared to Reyes-Heroles and Tenorio (2017) is that we use annual data, which better correspond to the timing of our model and existing literature. Quarterly GDP figures were annualized and then log-linearly detrended, and monthly interest rate data were averaged arithmetically. The estimated process is

$$
\left(\begin{array}{l}
z_{t} \\
r_{t}
\end{array}\right)=\left(\begin{array}{l}
0.0052 \\
0.0025
\end{array}\right)+\left(\begin{array}{cc}
0.6079 & -0.1321 \\
0.1289 & 0.8261
\end{array}\right)\left(\begin{array}{c}
z_{t-1} \\
r_{t-1}
\end{array}\right)+\left(\begin{array}{c}
\epsilon_{t}^{z} \\
\epsilon_{t}^{r}
\end{array}\right),
$$

\footnotetext{
${ }^{33}$ These numbers are calculated using data from the updated and extended External Wealth of Nations database of Lane and Milesi-Ferretti (2007). The figure corresponds to the countries in Sample 1 described in Reyes-Heroles and Tenorio (2017). As a reference, an alternative calibration target could have been the average net foreign asset to GDP ratio, which amounts to 27.8 percent of GDP in our sample.
} 
Figure 1: Evolution of Interest Rates and their Volatility in the Data
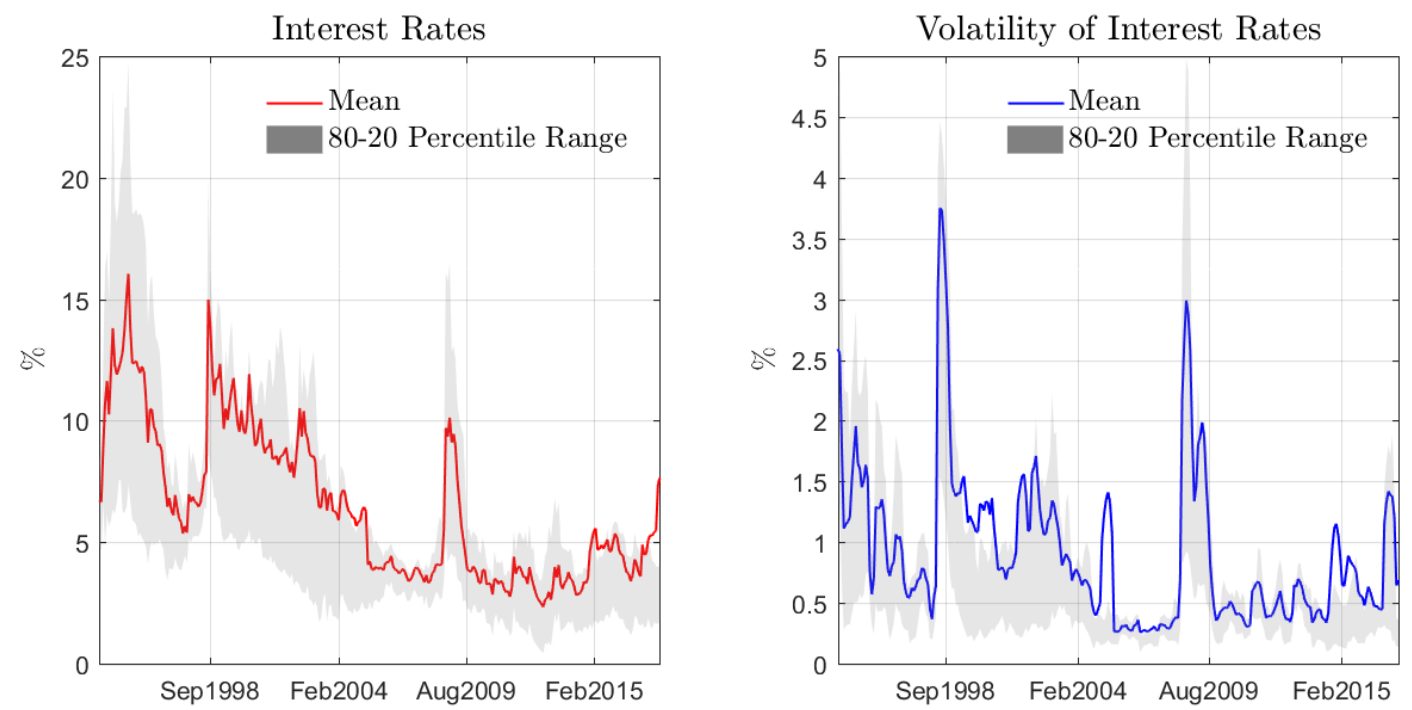

Note: For interest rates we consider J.P. Morgan's EMBIG (left panel). The measure of volatility shown in the right panel is the 7-month rolling standard deviation of the EMBIG. The countries included in our sample are Argentina, Brazil, Bulgaria, Chile, China, Colombia, Dominican Republic, Ecuador, Egypt, El Salvador, Hungary, Indonesia, Korea, Malaysia, Mexico, Nigeria, Pakistan, Panama, Peru, Philippines, Poland, Russia, South Africa, Turkey, Ukraine, Uruguay and Venezuela.

and the covariance and transition matrices are composed of

$$
\begin{aligned}
& \sigma^{z}=0.0312, \quad \rho=-0.4048, \quad \pi_{L}=0.9610, \\
& \sigma_{L}^{r}=0.0150, \quad \sigma_{H}^{r}=0.0661, \quad \pi_{H}=0.7468 \text {. }
\end{aligned}
$$

The results of our estimation are in line with those in Reyes-Heroles and Tenorio (2017), who estimate a similar process for a large sample of EMEs and provide evidence of the robust existence of multiple regimes in the volatility of interest rates. Reyes-Heroles and Tenorio (2017) also study the dynamics of external interest rates around sudden stop episodes and show that (i) sudden stops are preceded by periods of below-normal interest rates, which rise when a sudden stop occurs and revert to their normal levels in the following years, and that (ii) sudden stops follow periods of low interest rate volatility that increases sharply at the beginning of the sudden stop and remains persistently high for multiple periods. We will show in the following subsection that a typical sudden stop generated by our model occurs precisely when external shocks imply these dynamics for interest rates and their volatility.

The ergodic mean of the output and the interest rate processes can be obtained by inverting the VAR as follows:

$$
E\left(\begin{array}{c}
z_{t} \\
r_{t}
\end{array}\right)=\left(I-\hat{A}_{1}\right)^{-1} \hat{A}_{0}=\left(\begin{array}{l}
0.0066 \\
0.0196
\end{array}\right)
$$


where $\hat{A}_{0}$ and $\hat{A}_{1}$ denote the estimated matrices in (17). The long-run average of the external interest rate is thus 1.96 percent, which is considerably below the households' discount rate of $\left(\beta^{-1}-1\right) \approx 4$ percent. This difference gives the households an incentive to borrow from the exterior in order to consume up front.

The two regimes of the VAR have considerably different interest rate volatilities. In the low volatility regime, the standard deviation of interest rate shocks is small $\left(\sigma_{L}^{r}=1.50 \%\right)$, leading to a very low refinancing risk for bond holdings. In contrast, in the high volatility state, the standard deviation is 4.4 times higher $\left(\sigma_{H}^{r}=6.61 \%\right)$, which induces a large uncertainty regarding future access to debt financing for the economy. The transition matrix between the two volatility states has a high persistence: The mean duration of low and high volatility episodes is 25.6 and 3.9 years, respectively. In the long run, the economy spends 86.6 percent of the time in the low volatility state. Our estimates for the variance of the external interest rate are consistent with the findings in previous literature (for example, Fernández-Villaverde et al., 2011). ${ }^{34}$

We use a global solution method to characterize the recursive competitive equilibrium of the economy in a discretized version of the aggregate state space. We use a grid of 300 points for household savings, placing 80 percent of them around the region where the borrowing constraint binds in order to better capture the nonlinearities of the model. We discretize the estimated VAR process using a two-dimensional variation of the Tauchen (1986) method that allows for different levels of variance of the shocks. We use a grid of 7 points for output shocks and 15 points for the interest rate to better capture the effects of changing volatility of the latter variable. We truncate the grids in order to include 95 percent of the probability mass of shocks at the ergodic distribution, which was approximated by simulating the VAR for 1 million periods. To solve the system of rational expectations with occasionally binding constraints, we use an adaptation of the endogenous grid method of Carroll (2006). Appendix D describes in detail our algorithm. The next section describes the results our numerical solution.

\subsection{Description of the competitive equilibrium}

Figure 2 depicts the numerical solution of the recursive competitive equilibrium for a given exogenous state of the economy. In the first panel, we show the representative household's savings rule $\mathcal{B}(B, X)$ as a function of the initial level of aggregate savings $B$. This decision rule is non-monotonic: For high levels of wealth, the savings rule is upward sloping, as expected. Given that the average interest rate is below the households' discount factor, there is an incentive to

\footnotetext{
${ }^{34} \mathrm{~A}$ limitation of the process we estimate is that shocks to interest rates are symmetric: When volatility increases, it is equally likely for it to reach large deviations above or below the mean. We opt not to introduce asymmetries for the sake of parsimony and simplicity. An estimation of the VAR model with additional degrees of freedom could be conducted to assess the quantitative relevance of asymmetric shocks.
} 
Figure 2: Recursive competitive equilibrium: Savings rule, consumption, asset prices, and multiplier on the borrowing constraint.
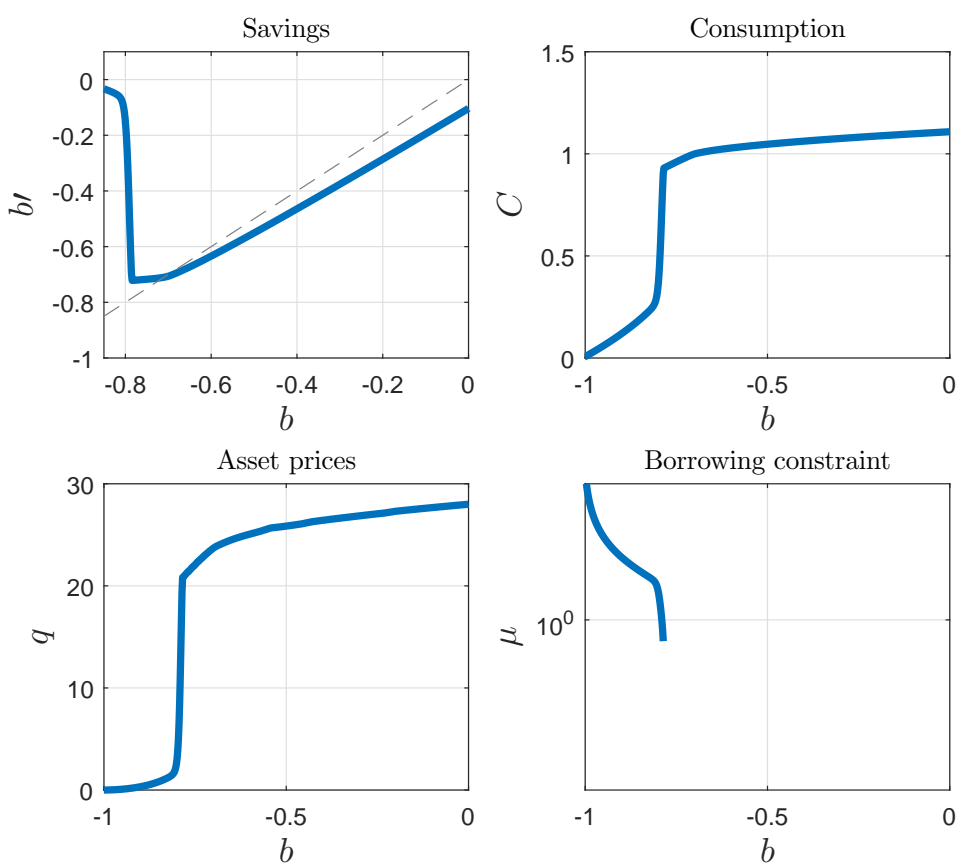

increase the economy's indebtedness, which is reflected in the fact that the savings rule lies below the 45 degree line. If the amount of debt reaches high enough levels, the borrowing constraint becomes binding. In this situation, the households must reduce their consumption in order to lower their stock of debt, as displayed in the second panel of the figure. This reduction causes an increase in the marginal utility of contemporaneous consumption, which in turn induces a higher discount of future cash flows and a consequent drop in asset prices. This drop is shown in the third panel, which depicts the equilibrium asset prices, $\mathcal{Q}(B, X)$, as a function of savings $B$. The sharp drop in the value of collateral forces a large deleveraging, as shown in the first panel, which feeds back into further consumption cuts and asset price falls, ad infinitum.

The sharp potential decline in consumption during crises leads to a greater precautionary savings motive by households when the probability of such events increases. The first panel of Figure 2 shows that the rate at which households become more indebted decreases around this region - the savings rule becomes flatter as the economy comes closer to the crisis region. Hence, the precautionary motive gains an increasing importance vis-à-vis the impatience motive in the households' problem.

We turn attention now to how households adjust their optimal decisions when faced with shocks to external risks. ${ }^{35}$ Figure 3 compares the savings decision rules for two different levels of the external interest rate. Away from the borrowing constraint, the interest rate has the usual

\footnotetext{
${ }^{35}$ Appendix E analyzes changes in saving decisions for income shocks.
} 
Figure 3: Savings rule: different levels of $r$

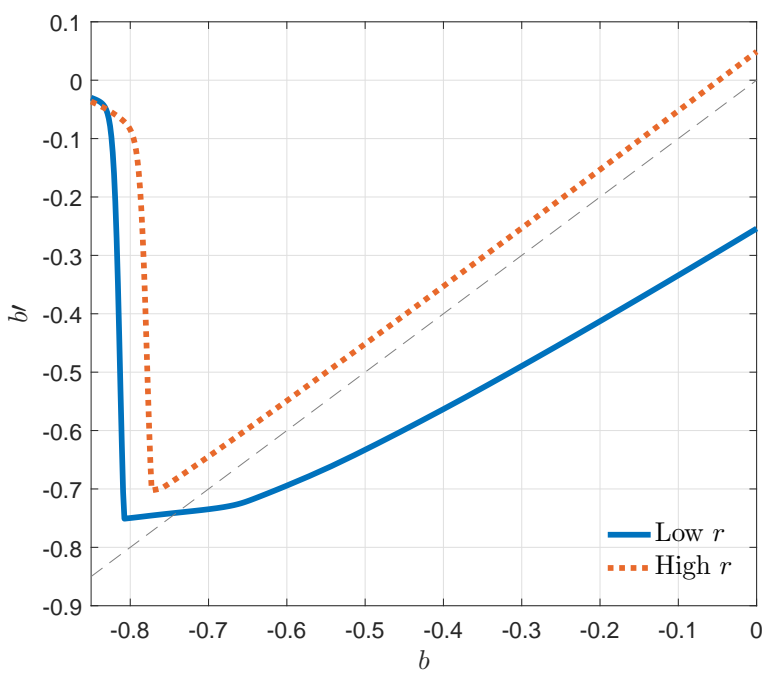

Figure 4: Savings rule: Different levels of $\sigma^{r}$

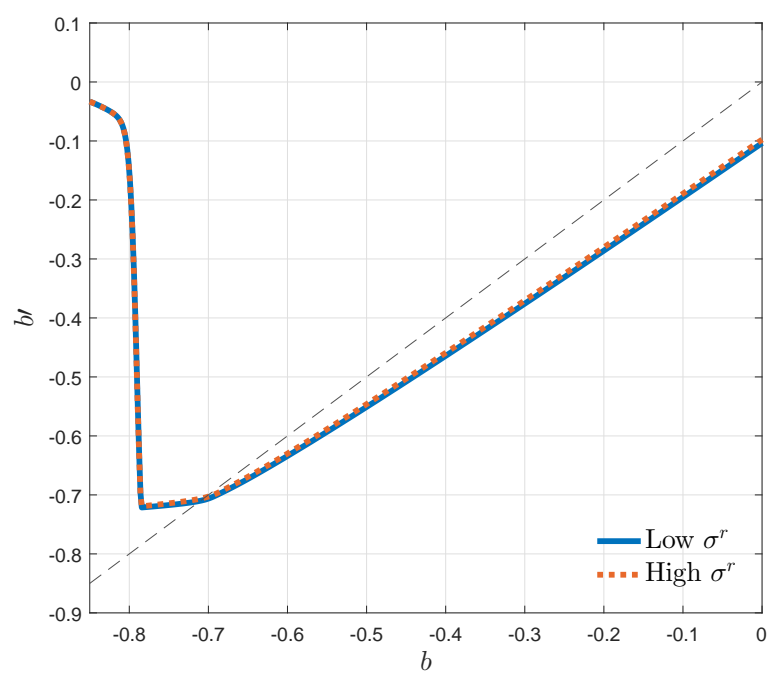

effect on the economy: When the country faces a higher cost of borrowing (orange dashed line), it tends to increase its savings. However, in the vicinity of the borrowing constraint, changes in the interest rate have an additional effect: An increase in the interest rate causes a decline in the stochastic discount factor (in expectation), which in turn reduces the value of the tree because its future flows are discounted more heavily. Hence, when the country faces higher interest rates, the value of collateral is lower and the borrowing constraint starts binding for lower levels of debt. ${ }^{36}$

In Figure 4 we compare the decision rules in the economy for two different levels of the variance of the external interest rate, $\sigma^{r}$. We keep the level of interest rates constant and compare the decision rules for the two levels of such variance. The figure shows that the savings rule for the high volatility state lies slightly above the one for low volatility. This outcome was expected because the households should have a higher precautionary saving motive when they face a world with higher uncertainty. Nonetheless, the magnitude of the difference between both decision rules is considerably small, so these shocks do not modify households' savings substantially.

It is important to highlight that the direct effect of more volatile interest rates is different from the direct effect of more volatile income shocks. While the precautionary motive that arises as a result of more volatile shocks to the dividend process is clear, the effect induced by more volatile interest rates affects the hedging properties of bonds. If the interest rate is more volatile, bonds become a worse hedging instrument against dividend shocks, thus leading to a decline in the demand for shares of the tree and, therefore, in their price. As shown in Figure 4, this

\footnotetext{
${ }^{36}$ The model generates interesting asymmetric responses to external. Appendix F analyzes the asymmetries generated by the nonlinear dynamics of the economy, given shocks to the level of external interest rates.
} 
Figure 5: Event study of typical crises
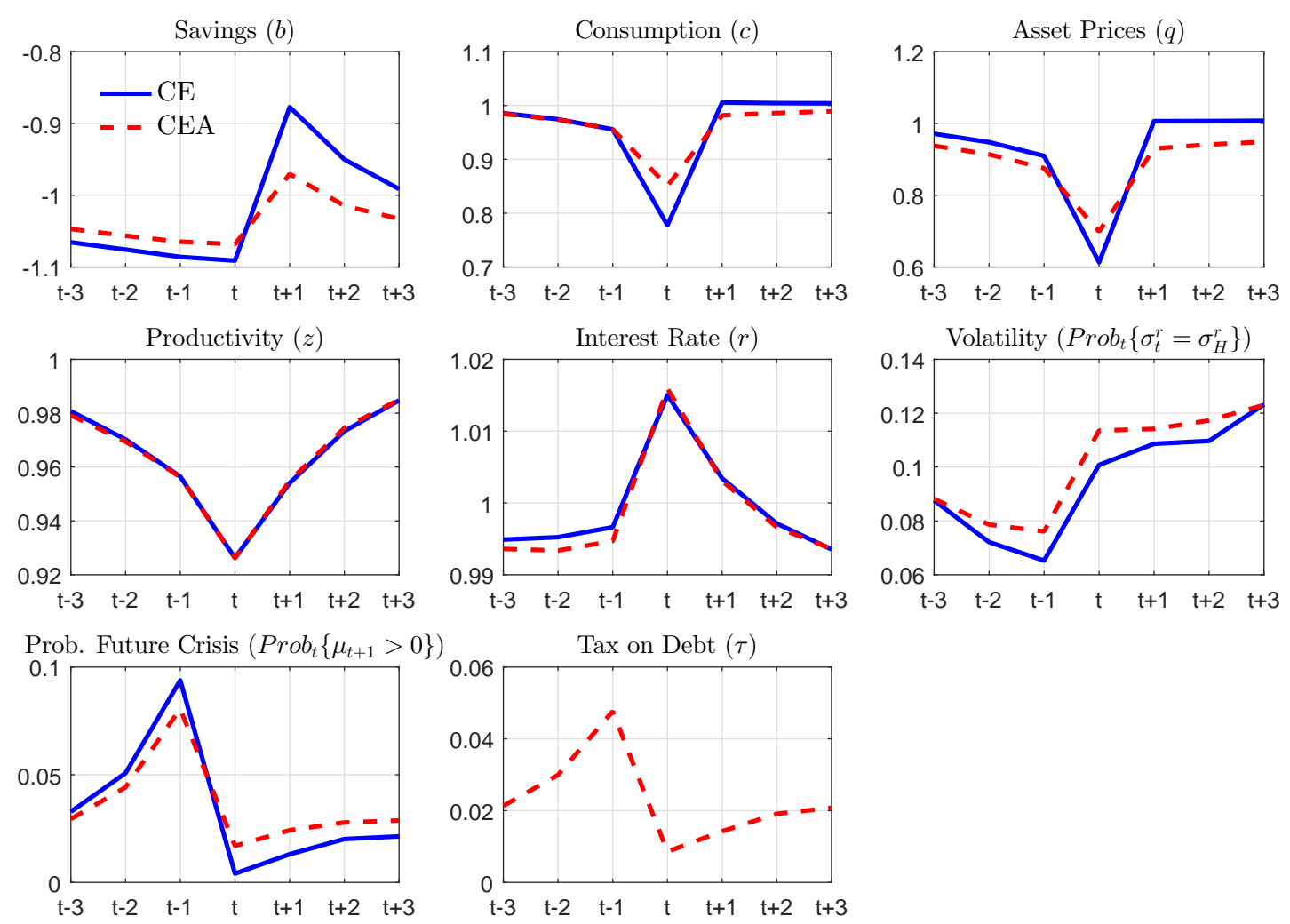

mechanism does not have significant effects on private agents' borrowing decisions. However, notice that changes equilibrium prices had an effect on the collateral that is not internalized by private agents, but that plays a key role for the decision of the planner. ${ }^{37}$

We now turn to the dynamics of the economy around crisis episodes. Figure 5 depicts the dynamics of the competitive equilibrium variables around a typical crisis (solid blue lines labeled

\footnotetext{
${ }^{37}$ In our model, the small effect of external volatility on equilibrium allocations arises from the absence of a complete production economy with capital accumulation. Fernández-Villaverde et al. (2011) include capital accumulation in an open economy facing shocks to the volatility of the external interest rates and show a significant response of real activity to these shocks. They also highlight the importance of external debt as a hedge against domestic income shocks and show that the real effects are mainly due to changes in investment decisions. Because most of the risk in households' consumption arises from shocks to the domestic productivity, the external locally-risk-free debt is a good hedge against domestic risk. However, when the rollover risk of external debt increases, foreign bonds are less useful as a hedge, which implies that the economy must cut on their holdings of capital to reduce exposure to domestic risk. The decline in investment causes a decrease in future output which reduces wealth and induces a reduction in consumption and foreign debt. Because we are interested in isolating the policy response of a planner that focuses on the incidence and severity of crises caused by collateral constraints, and given the complexity involved in solving for the time-consistent constrained efficient allocations, we do not incorporate capital accumulation and production in our framework. By introducing investment as in Fernández-Villaverde et al. (2011), we would be potentially increasing the planner's incentives to engage in ex ante and ex post interventions to reduce the incidence and severity of crises. We decide to leave this endeavor for future research.
} 
as CE). ${ }^{38}$ All the variables are divided by their average value in "normal times," that is, in periods in which the borrowing constraint is non-binding. The only exception is the panel for interest rate volatility (sixth panel), which shows the fraction of episodes in which the high volatility regime is prevailing. Each panel shows the normalized average of the variable from $t-3$ to $t+3$, where $t$ is the moment in which the borrowing constraint binds. In the first panel, we see that binding constraints arise from periods in which the economy has a relatively large stock of debt: The average level of debt before sudden stop periods is almost 10 percent higher than the average debt in non-binding periods. In the panels of the second row, we can see that binding borrowing constraints are typically accompanied by low levels of the endowment, $z$, and drastic increases in the interest rate, $r$.

To contrast our model with the empirical evidence, we follow the literature in associating a period in which a borrowing constraint binds in the model with the occurrence of a sudden stop in the data. From this perspective, the prevalence of sudden stops in the model is considerably lower than in the data. Under the typical definition of sudden stops considered in the literature, including in Reyes-Heroles and Tenorio (2017), the prevalence of these episodes in the sample of EMEs lies between 14.6 percent and 15.21 percent of the periods (measured in months), depending on the countries considered.

Nonetheless, the evolution of the modeled economy around sudden stops is consistent with the empirical evidence presented in Reyes-Heroles and Tenorio (2017) regarding the dynamics of the external interest rate. Both in the model and in the data, a sudden stop is associated with a sharp increase in the interest rate: The model predicts that sudden stops happen when the interest rate increases, on average, 1.5 percentage points with respect to the normal times' mean, whereas in the data, the interest rate increases between 1 and 2 percentage points in the 12 months that follow the beginning of such episodes. In addition, the model predicts that sudden stops take place after periods of relatively low interest rate volatility, precisely when volatility switches to the high regime, thus allowing for large upward shocks in the level of the interest rate. Again, this pattern is consistent with the sudden rise in volatility at the time of sudden stop episodes observed in the data.

The fourth panel of Figure 5 shows that crises are typically preceded by a sequence of negative output shocks and an abnormally large negative shock in the period in which the constraint binds. These shocks bring the level of output down almost 8 percent below its

\footnotetext{
${ }^{38}$ We simulate the model for 100,000 thousand periods to study the prevalence of binding borrowing constraints and their effects around these events. We find that in our baseline parameterization, a binding borrowing constraint is a rare event: It takes place in only 1.82 percent of the periods. Even in the periods preceding the actual occurrence of a binding constraint, the model assigns conditional probabilities to this event below 10 percent on average.
} 
normal times. These dynamics contrast with the empirical evidence in two respects. First, sudden stops are typically preceded by economic expansions (of around 1 percent in the sample studied by Reyes-Heroles and Tenorio (2017)). Second, the empirical output declines after crises are relatively modest, of around 2 percent relative to its normal times' level. In terms of consumption and asset prices, the dynamics of the model agree with the empirical patterns of balance of payment crises: These are usually accompanied with sharp declines in consumption and asset prices. However, the fall in consumption that arises in our model, of about 20 percent below the normal times level, is considerably higher than its empirical counterpart of about 2 percent or 3 percent in the countries studied by Korinek and Mendoza (2013). ${ }^{39}$

\subsection{The constrained efficient allocation and optimal policy}

We now turn to the numerical analysis of the constrained efficient allocation. We maintain the same parameterization as in the previous section to characterize quantitatively the solution to the planner's problem. In Appendix C.1 we show that the Euler equation for the planner's problem (14) simplifies to

$$
u^{\prime}(\mathcal{C}(B, X))-\mu(B, X)=R(X) \beta \mathbb{E}\left[u^{\prime}\left(\mathcal{C}\left(B^{\prime}, X^{\prime}\right)\right)+\kappa \mu\left(B^{\prime}, X^{\prime}\right) \psi\left(B^{\prime}, X^{\prime}\right)\right]
$$

given our assumption in footnote 32. For the remainder of the paper, we rely on equation (18) to describe the optimal decision rule of the planner and the associated equilibrium outcomes.

Figure 6 compares the savings rules for the households in the competitive equilibrium and the solution to the planner's problem. As Bianchi and Mendoza (2018) note, the savings rule in both problems are similar in most of the state space, but they differ considerably in what they call the "high externality region," where the borrowing constraint has a high probability of binding and the asset price schedule becomes steeper as a function of savings.

Even though the savings rules do not show large differences between the competitive equilibrium and the planner's problem, there are indeed important differences in the dynamics of both problems. ${ }^{40}$ In particular, the planner's actions have important effects on the severity of crises. For instance, we find that the planner is able to reduce the frequency of sudden stops from 1.82 percent of the periods in the competitive equilibrium to 1.61 percent in the constrained efficient allocation.

In Figure 5, we show event studies around the periods in which the borrowing constraint binds

\footnotetext{
${ }^{39}$ However, the drop in consumption in our model is for the marginal household.

${ }^{40}$ As the previous literature has pointed out, there are no large differences in allocations across steady states. Figure 18 in Appendix G shows that the amount of leverage in the planner's economy does not change considerably with respect to the competitive equilibrium.
} 
Figure 6: Savings rule: Constrained efficient allocation versus competitive equilibrium

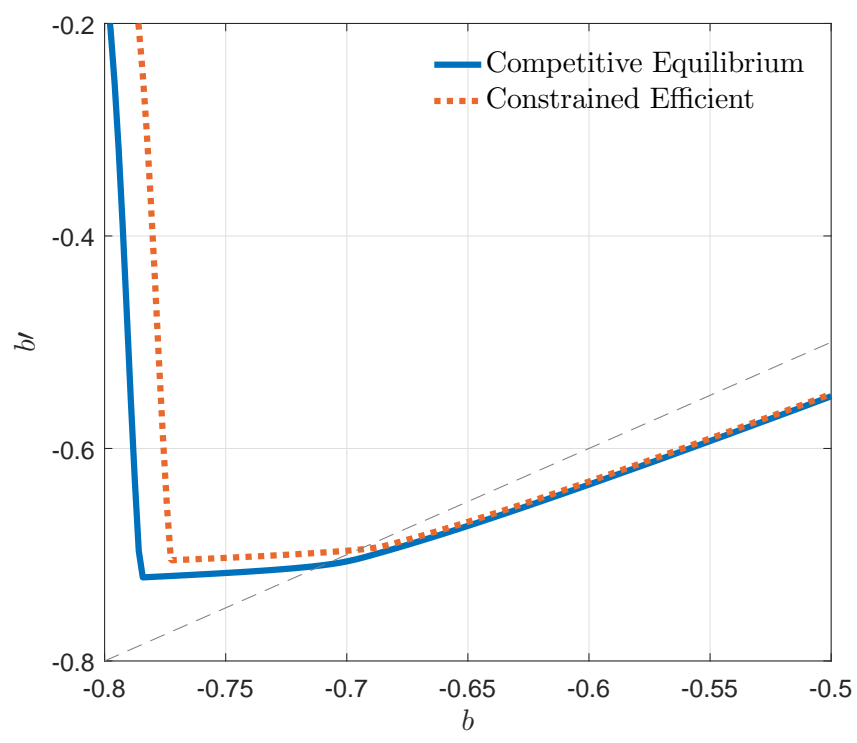

in the planner's economy. The outcomes corresponding to the planner's problem are depicted by red dashed lines. We observe that the consequences of a binding constraint are considerably milder in the planner's allocation compared to the competitive equilibrium: Consumption decreases by less, asset prices remain higher, and deleveraging is slower. Even though the average decline in the endowment is roughly the same in both economies, it takes a larger positive interest rate shock to hit the borrowing constraint in the constrained efficient economy. This shock is accompanied by a sudden increase in volatility that enables the interest rate shock to reach high realizations. One of the key features of the policy associated with the constrained efficient allocation is that it depresses asset prices in order to achieve its objective of decreasing the incidence and severity of crises. In doing so, it incentivizes households to decrease their leverage and increase savings. This feature will play a crucial role when we analyze the response of optimal policy to external shocks.

\subsubsection{Decentralization}

We now explore how the planner responds to the external shocks faced by the economy. We will focus on analyzing the state contingent macroprudential tax on debt that decentralizes the constrained efficient allocation. ${ }^{41}$ By comparing the equations that characterize the solution of

\footnotetext{
${ }^{41}$ There are other policy instruments that can decentralize the constrained efficient allocation. Bianchi and Mendoza (2018) provide some examples of such instruments; however, they focus on a tax on debt and we do the same here because we believe it provides a very intuitive perspective on how to influence capital flows across countries.
} 
the competitive equilibrium and the planner's problem (equations (8) and (18) respectively), it can immediately be seen that the wedge on the households' gross interest rate that implements the allocation of the planner's problem is

$$
\tau(B, X)=\frac{\mathbb{E}\left[\kappa \psi\left(B^{\prime}, X^{\prime}\right) \mu\left(B^{\prime}, X^{\prime}\right) \mid X\right]}{\mathbb{E}\left[u^{\prime}\left(c\left(B^{\prime}, X^{\prime}\right)\right) \mid X\right]},
$$

where $B^{\prime}=\Psi(B, X)$ is the optimal level of savings chosen by the planner when initial savings are $B$ and shocks $X$ are realized. From equation (19) we see that the size of the planner's intervention is determined by the expected marginal welfare gain of reducing households' indebtedness: The value of reducing households' debt by a unit is equal to the increase in the value of collateral, $\kappa \psi\left(B^{\prime}, X^{\prime}\right)$, times the marginal value of relaxing the collateral constraint, $\mu\left(B^{\prime}, X^{\prime}\right)$.

Figure 7 depicts the optimal $\operatorname{tax} \tau(B, X)$ as a function of $B$ for given levels of the exogenous state $X$. Notice first that, independently of the level of the interest rate, higher savings (to the right of the graph) imply that the borrowing constraint is less likely to bind, which makes the planner's intervention small or even null. Then, as debt starts accumulating, we see that the size of the tax increases. Two things happen: (i) The borrowing constraint is more likely to bind, and it becomes tighter, which delivers a higher expected multiplier $\mu\left(B^{\prime}, X^{\prime}\right)$, and (ii) the expected severity of the pecuniary externality, $\psi\left(B^{\prime}, X^{\prime}\right)$, declines. It turns out that the effect of a greater incidence of a potential future crisis dominates as debt increases, which is reflected in a higher macroprudential tax. ${ }^{42}$ In our numerical example, the tax rate amounts to a few percentage points over the gross interest rate, which considerably increases the after-tax interest rate paid by the households. In the figure, we also see that for higher levels of debt, the borrowing constraint binds and the households are forced to decrease their leverage drastically by the price-debt mechanisms of the model. This deleveraging brings the stock of debt away from the borrowing constraint for the immediate future. In this case, the tax on debt is zero because the economy is not constrained in the upcoming period. Thus, this model has no space for ex post intervention; the planner's actions to eliminate pecuniary externalities are only necessary before a borrowing constraint binds. ${ }^{43}$

Let us now turn to the analysis of the optimal tax for different levels of the external interest

\footnotetext{
${ }^{42}$ We turn to a more detailed analysis of the forces shaping the tax in the next subsection by decomposing it.

${ }^{43}$ See Benigno et al. (2013a). Figure 19 also shows that the macroprudential tax is always non-negative. The planner taxes "overborrowing," and thus expects to have positive effects on welfare through the internalization of the price externality. From equation (16), we also see that the size of the pecuniary externality must be non-negative because the utility function is strictly increasing and concave, and asset prices are non-negative throughout the state space. In addition, the effect of relaxing the collateral constraint is non-negative, because it necessarily increases welfare when the constraint binds, and has a null effect otherwise.
} 

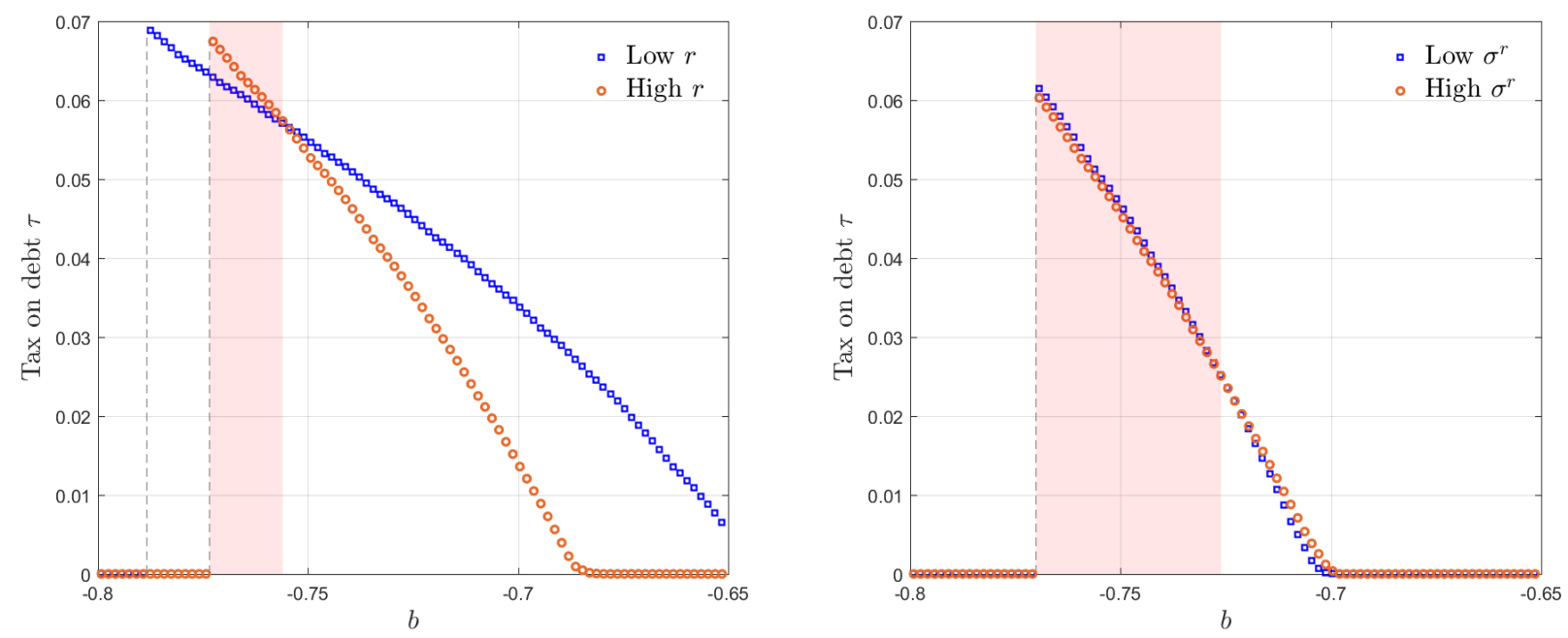

rate. ${ }^{44,45}$ Figure 7 shows the dependence of the optimal macroprudential tax on shocks to interest rates. The first thing we observe is that for high interest rates the optimal macroprudential tax is lower than for low interest rates for almost all levels of savings (non-shaded region). This is both in line with previous findings in the literature and intuitive: As the interest rate increases, the planner has a lower need to reduce households' borrowing because they do so themselves as an optimal response to higher costs of credit and lower value of collateral. However, Figure 7 also shows that this relationship is non-monotonic across levels of debt. For high levels of debt (shaded region), the optimal tax for high interest rates is larger than the one corresponding to low interest rates. The intuition behind this result derives from the fact that the increase in the precautionary motive by households when they're closer to the crisis region implies that higher interest rates generate larger declines in current consumption, asset prices and the value of collateral. This reduction increases the probability of states in the next period where the borrowing constraint binds, precisely when consumption is low and crises are more severe. Hence, the dependence of the optimal tax policy on the level of the interest rate depends on the endogenous state of the economy. ${ }^{46}$ Notice that underlying this result is the fact that the

\footnotetext{
${ }^{44}$ This analysis is similar to the one by Bianchi et al. (2016), and our results are partially consistent with theirs, as discussed below. However, a crucial difference is that they consider the case in which the real exchange rate is the relevant price driving the pecuniary externality. In addition, they focus on shocks to global liquidity interpreted as regime switches in external interest rates. We consider the case in which the external interest rate follows an $\operatorname{AR}(1)$ process with stochastic volatility.

${ }^{45}$ In Appendix D we analyze the optimal tax on debt, $\tau(B, X)$, for different levels of the endowment shock.

${ }^{46}$ This finding contrasts with exisitng work. For instance, Jeanne and Korinek (2010) compare the steady state value of the tax when the value of the endowment is kept constant for different interest rate levels. The authors find that the steady state level of the macroprudential tax is decreasing with respect to the external
} 
Figure 9: Optimal Tax Across Levels of $\sigma^{r}$ and $r$

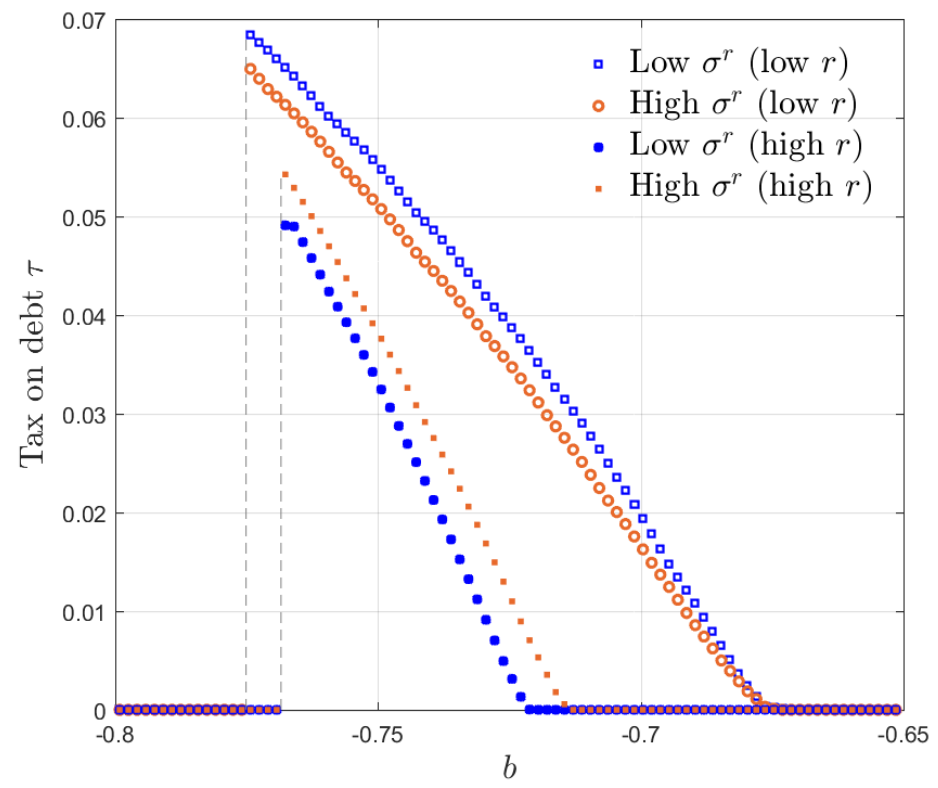

planner internalizes how changes in aggregate decisions by households given changes in interest rates affect asset prices and, therefore, the value of collateral. In the next subsection we study this interaction in more detail.

Next, we study how changes in the volatility of the external interest affect the optimal macroprudential tax. Figure 8 depicts the schedule of tax on debt as a function of household savings for the two different regimes of interest rate variability. Two main conclusions can be drawn from the effect of shocks to interest rate volatility on the planner's problem. First, the planner does indeed have a volatility-contingent optimal policy. This result can be better appreciated in Figure 9, where we depict the tax functions for each volatility regime, given different levels of the interest rate. This contingency contrasts with the result that the saving rule in the competitive equilibrium does not differ considerably across high and low volatility states (see Figure 4). These results together imply that shocks to volatility affect the incidence and severity of crises mainly through their effect on the pecuniary externality rather than through their implications for refinancing risks and private decisions. In the constrained efficient allocation, the planner's policy is affected by the volatility of interest rates because this volatility affects asset prices in the future which have implications for how likely the economy is to be in states in which the borrowing constraint binds.

interest rate. Our analysis, in contrast, studies the response of the entire schedule of taxes - as a function of the endogenous state variable - to shocks to external interest rates. Our result is also in contrast with the one in Bianchi et al. (2016) who show that, in their environment, the optimal macroprudential tax schedule for a low world interest rate lies above the one corresponding to the high interest rate. 
Figure 10: Histograms of tax on debt conditional on variance states
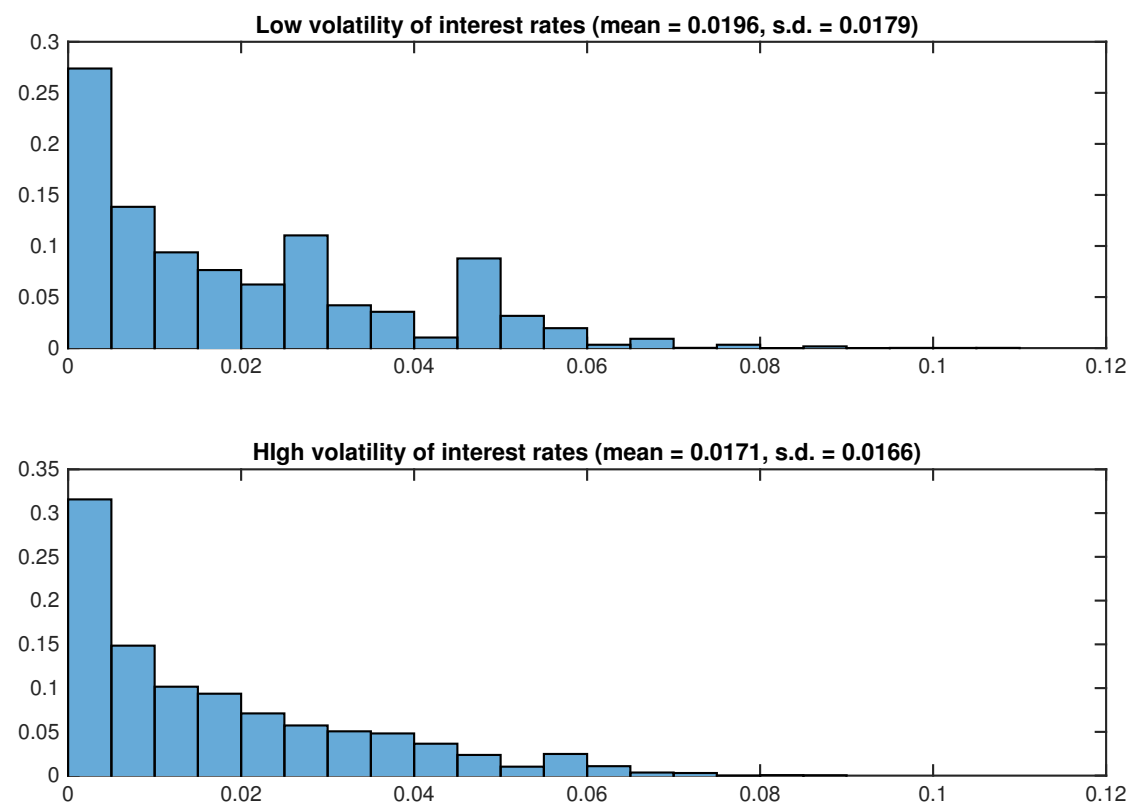

A second result that can be drawn from figures 8 and 9 is that the size of the optimal planner's intervention is non-monotonic with respect to the volatility of the interest rate. Figure 8 shows that there can exist interest rate levels for which there are certain levels of savings (shaded region) where the planner should intervene more when the volatility is high, but for other levels of savings the planner has a smaller intervention. Furthermore, Figure 9 shows that the direction of the change in the tax function can be opposite depending on the level of the interest rate. These issues follow from the fact mentioned in the previous paragraph that the planner is weighing two criteria when choosing the optimal tax on debt: the incidence of crises and the size of the pecuniary externality. In the following section we decompose how each of these two factors shapes the response of the planner to external shocks.

We also analyze the non-monotonic effect of volatility on taxes in the simulated economy to understand which direction of the response to volatility shocks prevails. We find that the share of states in which the planner chooses a zero tax on debt is larger when there is high variance than low variance: The planner sets a tax of zero in 59.6 percent of the periods of high volatility, versus 55.3 percent of low volatility periods. This difference can be understood by analyzing typical crises as shown in Figure 5. Notice that the typical crisis is preceded by low volatility of interest rates. Therefore, a positive tax should be imposed more often during periods of low volatility. The last panel of Figure 5 shows the evolution of the macroprudential tax around the occurrence of a sudden stop. We find that, prior to hitting the borrowing constraint, the 
planner imposes, on average, a tax on debt of around 3.5 percent. This tax significantly raises borrowing costs for households because the average interest rate they face is just 1.96 percent. Nonetheless, as we previously discussed, the planner does not engage in ex post macroprudential policies: The tax on debt when the borrowing constraint binds is close to zero, given the fact that there is a fast deleveraging taking place that makes it unlikely for a subsequent period to observe a binding borrowing constraint. Therefore, there is no motive for the planner to intervene during the period right after the borrowing was binding.

Figure 10 shows the ergodic distribution of the tax on debt, conditioning on low and high volatility states, and ignoring the periods of zero intervention. Positive interventions in low volatility periods average 1.96 percent, which is larger than the average positive intervention in high volatility periods of 1.71 percent. Moreover, the highest interventions in our simulations reach 10.7 percent and take place only in the low volatility state. In contrast, the highest intervention in the high volatility state is 8.92 percent. This last result is in line with Figure 8 , which shows that the macroprudential tax on debt reaches a higher maximum around high levels of indebtedness for the low volatility state.

\subsubsection{Decomposition of the optimal policy}

In this section we study in further detail the planner's response to the different shocks in the modeled economy. The results of our numerical exercises show that changes in the macroprudential tax due to exogenous shocks arise mainly because of differences in the numerator of (19) - the denominator remains fairly constant across different states as a result of the planner's desire to smooth consumption. Therefore, in this section, we decompose the numerator of the macroprudential tax into a product term and a covariance term in order to better understand the responses.

Notice that the denominator of (19) can be decomposed as

$$
\mathbb{E}\left[\kappa \psi\left(B^{\prime}, X^{\prime}\right) \mu\left(B^{\prime}, X^{\prime}\right)\right]=\kappa \mathbb{E}\left[\psi\left(B^{\prime}, X^{\prime}\right)\right] \cdot \mathbb{E}\left[\mu\left(B^{\prime}, X^{\prime}\right)\right]+\operatorname{Cov}\left(\kappa \psi\left(B^{\prime}, X^{\prime}\right), \mu\left(B^{\prime}, X^{\prime}\right)\right),
$$

where all the moments are conditional on the contemporaneous vector of shocks, $X$. Thus, the planner's intervention is larger when the planner (i) expects a higher likelihood and stringency of a binding constraint, defined as the incidence of the crisis $\left(\mu\left(B^{\prime}, X^{\prime}\right)\right)$ (ii) expects the size of the pecuniary externality taking place in the following period to be large, defined as the severity of the crisis $\left(\psi\left(B^{\prime}, X^{\prime}\right)\right)$; or (iii) expects these two factors to be highly correlated in the next period.

The intuition underlying the first two factors is clear, but the covariance term adds a level 
Figure 11: Decomposition of the tax: different interest rates
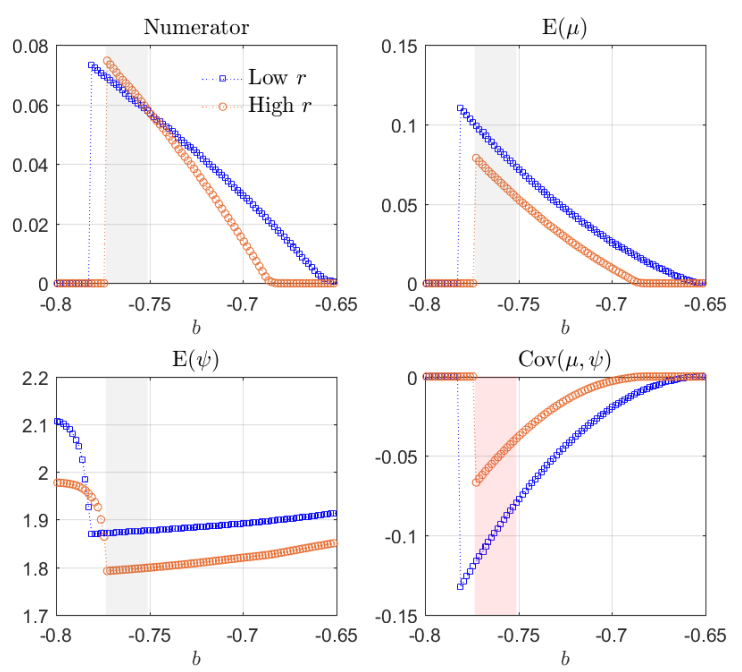

Figure 12: Decomposition of the tax: different interest rate volatilities
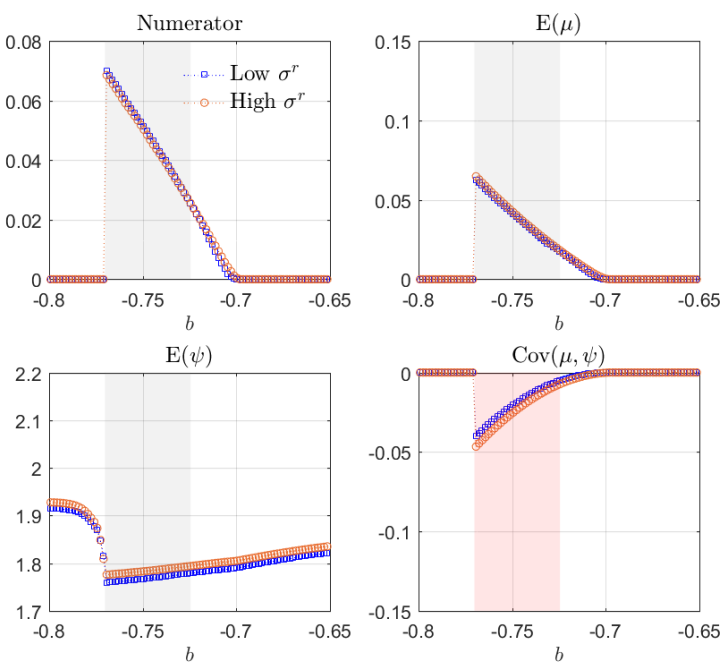

of complexity to the implementation of the optimal macroprudential tax. The rationale of how the last term affects the tax is also straightforward: Whenever high probabilities are assigned to states in which both the collateral constraint binds and the externality is very large, then the planner should increase the tax on debt. Thus, the larger the conditional covariance $\psi\left(B^{\prime}, X^{\prime}\right)$ and $\mu\left(B^{\prime}, X^{\prime}\right)$, the larger the planner's efforts to reduce the households' borrowing by increasing the tax on debt. As we explain in detail below, the covariance term is negative. Hence, an effective implementation of taxes to increase household welfare should take this factor into account and not reduce borrowing as much as when the incidence and the severity of the externality are seen as independent.

Figure 11 shows the decomposition of the optimal tax schedules plotted in Figure 7.47 We want to understand why the planner's intervention is lower when interest rates increase. From the figure we see that both the incidence of future crises and the severity of the associated externalities are expected to be lower when the interest rate increases. The latter effect is the result of a decrease in present and expected future asset prices due to the persistence of the positive shock to interest rates. The change in expected future prices is directly reflected on the severity of the externality in a crisis, as can be seen in (16). With respect to the incidence of the crisis, the increase in present and expected future interest rates incentivizes households to save more and decrease their leverage. These actions reduce the probability of a crisis in the future and therefore $\mathbb{E}_{t}\left[\mu_{t+1}\right]$. These two effects lead households facing a positive shock to the world

\footnotetext{
${ }^{47}$ The same decomposition for different income shocks is carried out in Appendix D.
} 
interest rate to increase savings and decrease consumption marginally, thus leading to a decrease in asset prices, which implies that the collateral constraint binds for lower levels of leverage.

However, notice that the covariance term counteracts these two forces and reduces the difference between the two policy schedules. The fourth panel in Figure 11 shows that the covariance effect is negative and increasing in absolute value with respect to indebtedness. The negative sign of the covariance term reflects the fact that states in which crises occur are also those in which asset prices are depressed. The depressed prices reduce the severity of the pecuniary externality in crisis states, as can be appreciated from (16). Notice also that the covariance term becomes more negative as debt increases. This occurs because consumption and asset prices decline as the economy approaches the crisis region. Hence, the future crises become more likely, but these are also associated with less drastic declines in asset prices.

Notice that the covariance term counteracts the greater effects of the expected incidence and severity of crises for low interest rates because it is higher (or less negative) when the interest rate takes on high levels. Even though the first two effects dominate over most levels of aggregate savings, thus leading to lower taxes for high interest rates, the covariance term decreases at a faster rates as debt increases when the interest rate is high. This effect implies that, for states in which the economy is highly indebted (shaded region), it is optimal to increase the tax given an increase in interest rates.

The increasing difference across interest rates in the covariance terms as the level of indebtedness increases arises from the fact that for the case with high interest rates, asset prices are depressed relative to the case with low interest rates. The depressed prices in turn imply that the size of the externality is even smaller the closer we get to the crisis zone (depressing prices even more), even though the incidence of future binding collateral constraints increase. Therefore, for very high levels of indebtedness it is optimal to increase the tax when interest rates increase because depressed current and future prices make the collateral constraint much more likely to bind in the immediate future, before households actually decrease indebtedness.

Finally, in Figure 12 we present the decomposition of the tax for the two interest rate volatility regimes, given the interest rate level considered in Figure 8. Notice that, for this particular case and opposite to the one with varying levels of the interest rate, high volatility implies that future crises are expected to be more likely and severe. For this type of exogenous shock, these two effects are also counteracted by the fact that the covariance term is more negative for high volatility. The incidence of a crisis increases with volatility because it increases the probability of higher interest rates in the future, thus leading to greater difficulty in refinancing current debt. Similarly, the expected severity of a crisis increase with volatility because high volatility leads to lower consumption and a potentially more severe crisis in the future. The intuition 

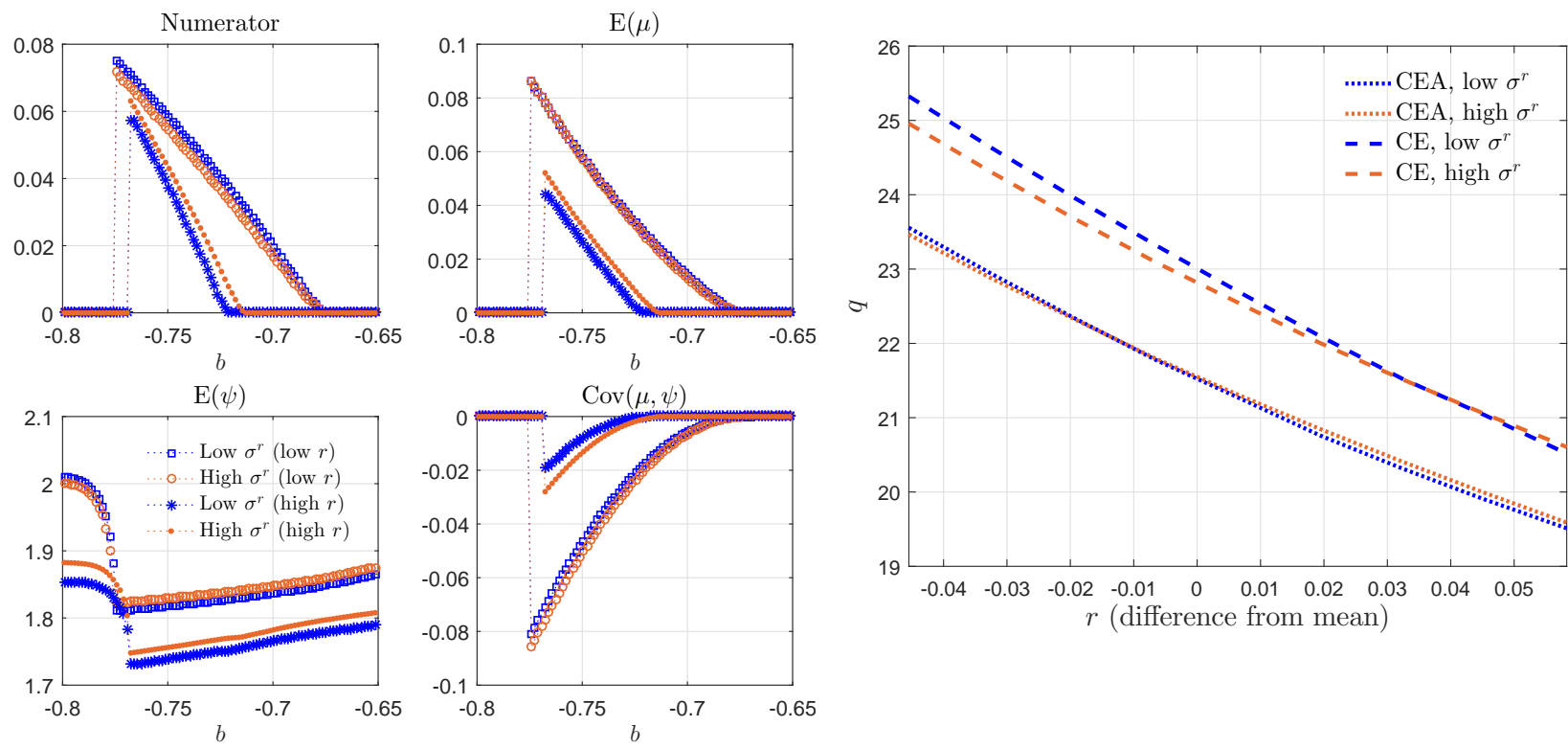

behind this result comes from the fact that debt becomes riskier when the interest rate is more volatile and, therefore, households want to hold less debt. To do so, households must decrease present consumption. ${ }^{48}$ The covariance counteracts these two effects and can actually be such that it leads both tax functions to cross as in Figure 12 and in the first panel of Figure 8. The covariance is more negative for high volatility because higher volatility increases precautionary savings by households that precisely make the more likely crisis also less severe.

The first two effects discussed in the previous paragraph suggest that higher interest rate volatility should call for higher macroprudential taxes on foreign borrowing, which is in line with simple common intuition. However, this is not necessarily the case as is shown over the shaded region of the endogenous state space. In this particular case, increased precautionary savings by households over this region of the state space imply that taxes should be lower for the high volatility regime. For low volatility, households acquire more debt and do not internalize the harm of a large drop in prices in a potential future crisis.

The decompositions corresponding to the tax functions in Figure 9, which are shown in Figure 13, help us better understand the nonmonotonicity of the optimal tax with respect to volatility shocks. The second panel of this figure shows that the nonmonotonicity is mainly driven by the effect of volatility on the incidence of crises. Given high interest rates leading to

\footnotetext{
${ }^{48}$ The fact that consumption today must be lower for high volatility can be seen in the equilibrium condition $\frac{1}{R_{t}}=\beta \frac{\mathbb{E}_{t}\left[u^{\prime}\left(c_{t+1}\right)\right]}{u^{\prime}\left(c_{t}\right)}$. Higher volatility in world interest rates leads to an increase in $\mathbb{E}\left[u^{\prime}\left(c_{t+1}\right)\right]$ by Jensen's inequality, and, given that $R_{t}$ does not change, $c_{t}$ must decrease in order for $u^{\prime}\left(c_{t}\right)$ to increase and make the equality hold.
} 
low asset prices, a shock increasing the volatility of interest rates clearly increases the incidence of future crises. However, for low interest rates associated with high asset prices, the same shock decreases the incidence of future crises. As shown in Figure 14, the main difference across these two cases is the effect that the volatility shock has on asset prices. Given a level of savings, for high interest rates an increase in volatility generates an increase in asset prices, while the effect is the opposite when interest rates are low. Given an increase in $\sigma^{r}$, households try to smooth the drop in consumption by selling some of their asset shares. The supply of assets leads to a decline in current asset prices and, therefore, in the value of collateral. This decline in the value of collateral is not an issue if asset prices are relatively high (interest rates are low). However, it could be the case that households increase their demand for assets as a precautionary motive to insure against future shocks. This is precisely what happens when asset prices are initally low (interest rates are high). ${ }^{49}$

Figure 14 also shows how the planner not only lowers prices relative to the competitive equilibrium, but also dampens the changes in prices generated by volatility shocks. This confirms the intial argument that volatility shocks affect the competitive equilibtium by affecting prices more than allocations. However, these changes in prices are internalized by the planner and therefore optimally responds to volatility shocks.

The decompositions of the optimal tax on debt show that the relations between external shocks and the incentives on the planner's problem are complex. The dynamics of the incidence and severity of crises are determined in general equilibrium and in response to forward-looking factors, and the ultimate policy prescriptions depend on the different forces acting in the economy. One important conclusion derived form the previous exercises is that simple policy prescriptions based on partial equilibrium rationales are insufficient to internalize the effect of "overborrowing" on asset prices and households' borrowing capacity, and they might lead to unintended consequences.

\section{Conclusion}

The increase in size and volatility of international capital flows in recent years carry inherent risks. The uncertainty regarding policy actions in industrialized economies as well as other underlying institutional and financial risks have increased the volatility of these flows. Policy makers around the world have grown concerned about the potential consequences of sudden reversals over their domestic financial sectors and ultimately on real economic activity. These

\footnotetext{
${ }^{49}$ Lower asset prices for high volatility is the case in line with the intuition and parametrization in FernándezVillaverde et al. (2011), in which investment falls after a positive shock to volatility.
} 
concerns have motivated a myriad of unconventional policy tools to moderate the movement and regulate the composition of capital flows across borders. The international community has recognized that the risks carried by the volatility of international flows call for a more thorough analysis of the design, and especially the implementation, of macroprudential policies (see IMF, 2012). This work contributes to our understanding of the implementation of this type of policy in an economy prone to sudden stop episodes in the face of external risks.

We extend the small open economy framework of Jeanne and Korinek (2010) and Bianchi and Mendoza (2018) to include shocks to the level and volatility of the interest rate faced by the economy, in the spirit of Fernández-Villaverde et al. (2011). We show that the dynamics of interest rates around episodes of sudden stops generated by the model have a similar behavior to those observed empirically in EMEs. The planner's interventions in response to shocks to the level and volatility of interest rates are complex and depend on more than just shocks in isolation. Two main lessons can be drawn from our analysis. First, for very low saving levels and depressed asset prices it is optimal to increase a macroprudential tax on borrowing given an increase in interest rate. However, this should not be the case for higher levels of savings. Second, while when asset prices are initially low, an increase in the volatility of interest rates calls for lower taxes, the opposite should be done when asset prices are relatively high.

The main lesson for policy makers facing a rise in external risks is that multiple factors should be taken into account when implementing macroprudential policies. Mere spikes in the volatility of external interest rates, like the ones observed in recent years as the international financial markets adjust to expected policy changes in industrialized economies, do not necessarily call for a higher macroprudential taxes. Policy makers should not only weigh the possibility of current account reversals to shape their interventions; they should also consider how external shocks affect the size of pecuniary externalities and the borrowing capacity of the country. 


\section{References}

Ahmed, Shaghil and Andrei Zlate, "Capital flows to emerging market economies: A brave new world?," International Finance Discussion Papers 1081, Board of Governors of the Federal Reserve System (U.S.) 2013.

Benigno, Gianluca, Huigang Chen, Christopher Otrok, Alessandro Rebucci, and Eric R. Young, "Revisiting Overborrowing and its Policy Implications," in Luis Felipe Céspedes, Roberto Chang, and Diego Saravia, eds., Monetary Policy under Financial Turbulence, Vol. 16 of Central Banking, Analysis, and Economic Policies Book Series, Central Bank of Chile, April 2011, chapter 6, pp. 145-184.

${ }_{-},,_{-}, \ldots$, and $\_,$"Financial crises and macro-prudential policies," Journal of International Economics, 2013, 89 (2), 453-470.

_, , , , , and Eric Young, "Capital Controls or Real Exchange Rate Policy? A Pecuniary Externality Perspective," Research Department Publications IDB-WP-393, Inter-American Development Bank, Research Department March 2013.

Bernanke, Ben S., Mark Gertler, and Simon Gilchrist, "The financial accelerator in a quantitative business cycle framework," in J. B. Taylor and M. Woodford, eds., Handbook of Macroeconomics, Vol. 1 of Handbook of Macroeconomics, Elsevier, 1999, chapter 21, pp. 13411393.

Bianchi, Javier, "Overborrowing and Systemic Externalities in the Business Cycle," American Economic Review, December 2011, 101 (7), 3400-3426.

_ and Enrique G. Mendoza, "Overborrowing, Financial Crises and 'Macro-prudential' Policy," 2011 Meeting Papers 175, Society for Economic Dynamics 2011.

_ and _ , "Optimal Time-Consistent Macroprudential Policy," Journal of Political Economy, 2018, $126(2)$, 588-634.

_, Chenxin Liu, and Enrique G. Mendoza, "Fundamentals news, global liquidity and macroprudential policy," Journal of International Economics, 2016, 99, Supplement 1, S2 S15. 38th Annual $\{$ NBER\} International Seminar on Macroeconomics.

Calvo, Guillermo A., Leonardo Leiderman, and Carmen M. Reinhart, "Inflows of Capital to Developing Countries in the 1990s," Journal of Economic Perspectives, June 1996, 10 (2), 123-139.

Carrière-Swallow, Yan and Luis Felipe Cépedes, "The impact of uncertainty shocks in emerging economies," Journal of International Economics, 2013, 90 (2), 316-325. 
Carroll, Christopher D, "The method of endogenous gridpoints for solving dynamic stochastic optimization problems," Economics letters, 2006, 91 (3), 312-320.

Chang, Roberto and Andres Fernández, "On The Sources Of Aggregate Fluctuations In Emerging Economies," International Economic Review, November 2013, 54, 1265-1293.

Fernández-Villaverde, J., P. Guerrón-Quintana, J. F. Rubio-Ramírez, and M. Uribe, "Risk Matters: The Real Effects of Volatility Shocks," American Economic Review, October 2011, 101 (6), 2530-61.

Fernández-Villaverde, Jesús and Juan Rubio-Ramírez, "Macroeconomics and Volatility: Data, Models, and Estimation," NBER Working Papers 16618, National Bureau of Economic Research, Inc December 2010.

IMF, "The Liberalization and Management of Capital Flows: An Institutional View," Technical Report, International Monetary Fund November 2012.

Jeanne, Olivier and Anton Korinek, "Managing Credit Booms and Busts: A Pigouvian Taxation Approach," NBER Working Papers 16377, National Bureau of Economic Research, Inc September 2010.

_ and _, "Macroprudential Regulation Versus Mopping Up After the Crash," NBER Working Papers 18675, National Bureau of Economic Research, Inc January 2013.

Johri, Alok, Shahed K. Khan, and César Sosa-Padilla, "Interest Rate Uncertainty and Sovereign Default Risk," Manuscript, University of Notre Dame 2015.

Kiyotaki, Nobuhiro and John Moore, "Credit Cycles," Journal of Political Economy, April 1997, 105 (2), 211-48.

Klein, Paul, Vincenzo Quadrini, and Jose-Victor Ríos-Rull, "Optimal time-consistent taxation with international mobility of capital," Advances in Macroeconomics, 2005, 5 (1), 2.

Korinek, Anton, "The New Economics of Prudential Capital Controls: A Research Agenda," IMF Economic Review, August 2011, 59 (3), 523-561.

_ and Enrique G. Mendoza, "From Sudden Stops to Fisherian Deflation: Quantitative Theory and Policy Implications," NBER Working Papers 19362, National Bureau of Economic Research, Inc August 2013.

Lane, Philip R and Gian Maria Milesi-Ferretti, "The external wealth of nations mark II: Revised and extended estimates of foreign assets and liabilities, 1970-2004," Journal of International Economics, 2007, 73 (2), 223-250. 
Longstaff, Francis A., Jun Pan, Lasse H. Pedersen, and Kenneth J. Singleton, "How Sovereign Is Sovereign Credit Risk?," American Economic Journal: Macroeconomics, April 2011, 3 (2), 75-103.

Lorenzoni, Guido, "Inefficient Credit Booms," The Review of Economic Studies, 2008, 75 (3), 809-833.

Mackowiak, Bartosz, "External shocks, U.S. monetary policy and macroeconomic fluctuations in emerging markets," Journal of Monetary Economics, November 2007, 54 (8), 2512-2520.

Mendoza, Enrique G., "Sudden Stops, Financial Crises, and Leverage," American Economic Review, December 2010, 100 (5), 1941-66.

- and Katherine A. Smith, "Quantitative Implications of a Debt-deflation Theory of Sudden Stops and Asset Prices," Journal of International Economics, September 2006, 70 (1), 82-114.

Miranda-Agrippino, Silvia and Hlne Rey, "US Monetary Policy and the Global Financial Cycle," Working Paper 21722, National Bureau of Economic Research November 2015.

Neumeyer, Pablo A. and Fabrizio Perri, "Business cycles in emerging economies: The role of interest rates," Journal of Monetary Economics, March 2005, 52 (2), 345-380.

Rey, Hlne, "Dilemma not Trilemma: The Global Financial Cycle and Monetary Policy Independence," Working Paper 21162, National Bureau of Economic Research May 2015.

Reyes-Heroles, Ricardo and Gabriel Tenorio, "Interest Rate Volatility and Sudden Stops : An Empirical Investigation," International Finance Discussion Papers 1209, Board of Governors of the Federal Reserve System (U.S.) July 2017.

Schmitt-Grohé, Stephanie and Martín Uribe, "Is Optimal Capital Control Policy Countercyclical in Open Economy Models with Collateral Constraints?," IMF Economic Review, Aug 2017, 65 (3), 498-527.

Tauchen, George, "Finite state markov-chain approximations to univariate and vector autoregressions," Economics letters, 1986, 20 (2), 177-181.

Uribe, Martin and Vivian Z. Yue, "Country spreads and emerging countries: Who drives whom?," Journal of International Economics, June 2006, 69 (1), 6-36. 


\section{Appendix}

\section{A Microeconomic foundations of the model}

\section{A.1 The timing of borrowing and asset trading}

Deriving the collateral constraint We show that the collateral constraint faced by households in (4) can be derived from incentive compatibility constraints on the borrowers in an environment in which limited enforcement prevents lenders from collecting more than a fraction $\kappa$ of the value of the asset, $s_{t+1}$, owned by a defaulting debtor.

We denote the individual and aggregate household choice variables with lowercase and uppercase letters, respectively. We divide any given period into three subperiods: morning, afternoon, and night (see Figure 15).

The period begins in the morning with aggregate asset holdings $(B, S)$ carried over from the night of the previous period. The realization of the external shocks $X=\left(z, r, \sigma^{r}\right)$ takes place at the beginning of the morning, and individual households receive the dividends from their holdings of the tree, $s \cdot d \exp (z)$. In this subperiod, there is perfect enforcement of debt contracts, so the household fully repays its outstanding debt $b$. Each household makes an optimal consumption and portfolio decision $\left(\hat{c}, \hat{b}^{\prime}, \hat{s}^{\prime}\right)$ subject to its budget constraint, (2), taking the morning price $\mathcal{Q}(B, X)$ and interest rate $R \exp (r)$ as given. At this point, that is, at the end of the morning, the choice of $\hat{c}$ is just a plan. Every household carries the physical goods it has designated to consume into the following subperiods given that consumption occurs at night.

Given the previous assumptions, the recursive problem of a household is such that its value in the morning is given by

$$
V^{m}(b, s, B, X)=\max _{\hat{c}, \hat{b}^{\prime}, \hat{s}^{\prime}}\left\{V^{a}\left(\hat{c}, \hat{b}^{\prime}, \hat{s}^{\prime}, B, X\right)\right\}
$$

subject to

$$
\hat{c}+\mathcal{Q}(B, X) \hat{s}^{\prime}+\frac{\hat{b}^{\prime}}{R(X)}=[\mathcal{Q}(B, X)+d(X)] s+b
$$

where $V^{a}\left(\hat{c}, \hat{b}^{\prime}, \hat{s}^{\prime}, B, X\right)$ denotes the value of the household in the afternoon.

In the afternoon, an individual household is holding a portfolio of assets $\left(\hat{b}^{\prime}, \hat{s}^{\prime}\right)$, and has $\hat{c}$ units of consumption goods to eat at night. At this point, the household has the possibility of diverting current stocks - and therefore the corresponding revenues that will become available when markets reopen at night — and default on its outstanding debt with the foreign lender next period. Therefore, the problem of the household choosing whether to default or not in the 
Figure 15: Timing of Actions

\begin{tabular}{|c|c|c|}
\hline $\begin{array}{l}\text { Household: chooses optimaly } \\
\left(\hat{b}^{\prime}, \hat{s}^{\prime}, \hat{c}\right) \text { given } \mathcal{Q} \text { and } R . \\
\text { At this point } \rightarrow \hat{c} \text { is a plan. }\end{array}$ & $\begin{array}{l}\text { - Lender: does not oberve } \\
\text { Household's actions. } \\
\text { - Household: given }\left(\hat{b}^{\prime}, \hat{s}^{\prime}, \hat{c}\right) \\
\rightarrow \text { can divert }(1-\kappa) \hat{s}^{\prime} \text { and } \\
\text { decide to default. }\end{array}$ & $\begin{array}{l}\text { - Lender: actions revealed to. } \\
\quad \rightarrow \text { confiscate } \kappa \hat{s}^{\prime} \text { in country and } \\
\text { sell for } \mathcal{Q}^{c} \text { and lend at } R \\
\text { - Household: can choose final } c \text {, } \\
\text { regain access to asset and } \\
\text { credit markets. }\end{array}$ \\
\hline Morning & Afternoon & Night \\
\hline
\end{tabular}

afternoon is simply given by

$$
V^{a}\left(\hat{c}, \hat{b}^{\prime}, \hat{s}^{\prime}, B, X\right)=\max \left\{V^{d}\left(\hat{c}, \hat{b}^{\prime}, \hat{s}^{\prime}, B, X\right), V^{r}\left(\hat{c}, \hat{b}^{\prime}, \hat{s}^{\prime}, B, X\right)\right\}
$$

where $V^{d}\left(\hat{c}, \hat{b}^{\prime}, \hat{s}^{\prime}, B, X\right)$ and $V^{r}\left(\hat{c}, \hat{b}^{\prime}, \hat{s}^{\prime}, B, X\right)$ denote the values at night of having defaulted or not in the afternoon respectively.

At night, the international lender finds out whether it has been defaulted. The lender is entitled to obtain the fraction $\kappa \in(0,1)$ of the household's stockholdings - the fraction that is not diverted - and the household regains immediate access to credit markets. The lender, nevertheless, cannot directly receive dividends from the tree, so it must sell it to local households in order to obtain a profit. We denote by $\mathcal{Q}^{c}(B, X)$ the prevailing price for this transaction in the night market. The lender then proceeds to loan the receipts of the transaction in the international financial markets - which include any households that might have defaulted - at the prevailing risk-free interest rate, $R \exp (r) .{ }^{50}$

Households can borrow again from the same lender, buy assets at the prevailing price, and exchange consumption goods, but there is no longer the possibility of diverting resources. However, the problem of a household differs if it diverted in the afternoon. Then, if the household decides to default, the value of this decision is given by

$$
\begin{aligned}
V^{d}\left(\hat{c}, \hat{b}^{\prime}, \hat{s}^{\prime}, B, X\right) & =\max _{c, b^{\prime}, s^{\prime}}\left\{u(c)+\beta \mathbb{E}\left[V^{m}\left(b^{\prime}, s^{\prime}, B^{\prime}, X^{\prime}\right) \mid X\right]\right\} \text { s.t. } \\
c+\mathcal{Q}^{c}(B, X) s^{\prime}+\frac{b^{\prime}}{R(X)} & =(1-\kappa) \mathcal{Q}^{c}(B, X) \hat{s}^{\prime}+\hat{c},
\end{aligned}
$$

\footnotetext{
${ }^{50}$ Because the interest rate is positive and the evolution of the stock prices does not in general have a positive trend, the lender has incentives to immediately sell the stocks and lend the revenue in the overnight market. Otherwise, we can assume that the holdings of the tree depreciate overnight when held by the lender, so he has incentives to immediately sell them.
} 
while if it repays, the corresponding value is

$$
\begin{aligned}
V^{r}\left(\hat{c}, \hat{b}^{\prime}, \hat{s}^{\prime}, B, X\right) & =\max _{c, b^{\prime}, s^{\prime}}\left\{u(c)+\beta \mathbb{E}\left[V^{m}\left(b^{\prime}, s^{\prime}, B^{\prime}, X^{\prime}\right) \mid X\right]\right\} \text { s.t. } \\
c+\mathcal{Q}^{c}(B, X) s^{\prime}+\frac{b^{\prime}}{R(X)} & =\frac{\hat{b}^{\prime}}{R(X)}+\mathcal{Q}^{c}(B, X) \hat{s}^{\prime}+\hat{c},
\end{aligned}
$$

given that it needs to maintain resources equal to $-\frac{\hat{b}^{\prime}}{R(X)}$ from its remaining wealth in order to repay tomorrow.

A graphical representation of the timing of borrowing and asset trading in this environment is presented in Figure 15.

Starting from the problem of the household at night, it can be clearly seen that the value of repaying will exceed that of defaulting, that is,

$$
V^{r}\left(\hat{b}^{\prime}, \hat{s}^{\prime}, B, X\right) \geq V^{d}\left(\hat{b}^{\prime}, \hat{s}^{\prime}, B, X\right)
$$

whenever

$$
-\frac{\hat{b}^{\prime}}{R(X)} \leq \kappa \mathcal{Q}^{c}(B, X) \hat{s}^{\prime}
$$

which is the collateral constraint that we use in the model. In words, to avoid losses from household default, lenders constrain the amount that they lend, $-b^{\prime} / R \exp (r)$, to be less than or equal to the market value of the household's asset holdings that cannot be diverted, $\kappa \mathcal{Q}^{c}(B, X) s^{\prime}$. This limit justifies the presence of the borrowing constraint (3) in the problem of the representative household. ${ }^{51}$

Pricing relationships in equilibrium Asset prices in the morning and at night must satisfy particular arbitrage conditions in the equilibrium we consider. First, our assumption that households compete à la Bertrand for the stocks of the tree at night implies that the market price of the tree at night, $\mathcal{Q}^{c}(B, X)$, is as high as the representative household prices the dividend payouts and resale value next period, according to the following Euler equation:

$$
\mathcal{Q}^{c}(B, X)=\beta \mathbb{E}\left[\frac{u^{\prime}\left(\mathcal{C}\left(\mathcal{B}(B, X), X^{\prime}\right)\right)\left[\mathcal{Q}\left(\mathcal{B}(B, X), X^{\prime}\right)+d\left(X^{\prime}\right)\right]}{u^{\prime}(\mathcal{C}(B, X))} \mid X\right]
$$

where $\mathcal{C}$ and $\mathcal{B}$ denote the aggregate decision rules of the economy.

It only remains to explain the equilibrium relationship between the morning and the night prices, $\mathcal{Q}$ and $\mathcal{Q}^{c}$ respectively. Assume that we impose the collateral constraint on the household's

\footnotetext{
${ }^{51} \mathrm{~A}$ crucial assumption we need to make in order for there to exist an equilibrium in this environment is that international lenders must lend in both the morning and night markets. Another way to have an equilibrium with such a pricing relationship would be by assuming that the household undertakes borrowing in both subperiods with just one foreign lender. This assumption can be justified by introducing an infinitesimally small fixed cost of borrowing with each additional competitive lender.
} 
problem in the morning in order to avoid default. Now, consider an equilibrium in which the borrowing constraint is binding, so that $\mu(B, X)>0$. For every additional stock of the tree that the household buys in the morning, it must sacrifice $\mathcal{Q}(B, X)$ units of consumption that are valued at the marginal utility $u^{\prime}(\hat{\mathcal{C}}(B, X))$. However, by buying more stocks of the tree, the representative household relaxes the borrowing constraint, and obtains a marginal benefit of $\kappa \mu(B, X) \mathcal{Q}^{c}(B, X)$, in the same subperiod. Thus, the net marginal cost of saving in stocks of the tree in the morning is

$$
\mathcal{Q}(B, X) u^{\prime}(\hat{\mathcal{C}}(B, X))-\kappa \mu(B, X) \mathcal{Q}^{c}(B, X)
$$

At night, the household can sell these stocks at the prevailing price, $\mathcal{Q}^{c}(B, X)$, which is valued at the marginal utility of consumption $u^{\prime}(\mathcal{C}(B, X))$. Thus, for the household demand of stocks to be optimal, it must be the case that the marginal cost in the morning equates the marginal benefit in the afternoon:

$$
\mathcal{Q}(B, X) u^{\prime}(\hat{\mathcal{C}}(B, X))-\kappa \mu(B, X) \mathcal{Q}^{c}(B, X)=\mathcal{Q}^{c}(B, X) u^{\prime}(\mathcal{C}(B, X))
$$

However, notice that the envelope conditions for the household's problems in the morning and at night imply that $u^{\prime}(\hat{\mathcal{C}}(B, X))=u^{\prime}(\mathcal{C}(B, X))$. Hence, we obtain the relationship between both asset prices which implies that whenever the borrowing constraint binds, the value of the tree in the morning will be higher than at night because holding the asset in the morning helps the households relax the borrowing constraint and increase their debt. The decrease in prices from the morning to the night is perfectly foreseen by every agent in the economy, but there are no arbitrage opportunities because it is forbidden to hold the asset in short positions.

The planner's intervention The social planner understands that the current aggregate level of debt, $B$, and the choice of future indebtedness, $B^{\prime}$, affect the value of collateral available in the economy and thus constrains the borrowing possibilities of the households. In order to internalize this pecuniary externality, the planner can control the households' borrowing decisions that take place in the morning, $B$.

Nonetheless, the planner cannot overcome the fact that households can divert their asset holdings in the afternoon and default on their outstanding debt. Moreover, the planner cannot intervene in the night stock market, in which the defaulted foreign lenders sell the remaining fractions of the diverted asset and regain access to credit markets. Thus, the planner faces the same borrowing constraint as the households (3), and the price of the assets must be consistent with the household Euler equation of stocks:

$$
\mathcal{Q}(B, X)=\beta E\left[\frac{u^{\prime}\left(\mathcal{C}\left(\mathcal{B}(B, X), X^{\prime}\right)\right)\left[\mathcal{Q}\left(\mathcal{B}(B, X), X^{\prime}\right)+d\left(X^{\prime}\right)\right]}{u^{\prime}(\mathcal{C}(B, X))} \mid X\right]
$$


In this case, the market price of the stocks is the same throughout the day because households do not internalize the effect of their savings in stocks on the borrowing possibilities for the planner's problem.

\section{B Competitive equilibrium}

Consider the recursive formulation of the household's problem, expressed in program (4). The solution to the household's problem is characterized by a pair of optimal decision rules for bonds and stocks, $\hat{b}(b, s, B, X)$ and $\hat{s}(b, s, B, X)$ respectively, that satisfy the following set of equations:

$$
\begin{aligned}
u^{\prime}(c) & =\mu(b, s, B, X)+\beta R(X) \mathbb{E}\left[u^{\prime}\left(c^{\prime}\right) \mid X\right], \text { and } \\
\mathcal{Q}(B, X) u^{\prime}(c) & =\beta \mathbb{E}\left[u^{\prime}\left(c^{\prime}\right)\left(\mathcal{Q}\left(\mathcal{B}(B, X), X^{\prime}\right)+d\left(X^{\prime}\right)\right) \mid X\right] \\
& +\mathcal{Q}^{c}(B, X) \mu(b, s, B, X) \kappa,
\end{aligned}
$$

the budget constraint of the household in each period, and the collateral constraint

$$
-\frac{\hat{b}(b, s, B, X)}{R(X)} \leq \kappa \mathcal{Q}^{c}(B, X) \hat{s}(b, s, B, X) .
$$

We now proceed to define a recursive competitive equilibrium.

Definition A recursive competitive equilibrium of this economy consists of pricing functions $\hat{\mathcal{Q}}(B, X)$ and $\hat{\mathcal{Q}}^{c}(B, X)$, a perceived law of motion for aggregate bond holdings, $\hat{\mathcal{B}}(B, X)$, and decision rules for households, $\hat{b}(b, s, B, X)$ and $\hat{s}(b, s, B, X)$, with associated value function $\hat{V}(b, s, B, X)$ such that:

1. Given $\hat{\mathcal{Q}}(B, X), \hat{\mathcal{Q}}^{c}(B, X)$ and $\mathcal{B}(B, X)$, households' decision rules, $\hat{b}(b, s, B, X)$ and $\hat{s}(b, s, B, X)$, and the associated value function $\hat{V}(b, s, B, X)$ solve the recursive problem of the household given by (4).

2. $\hat{\mathcal{B}}(B, X)$ is consistent with the actual law of motion for bond holdings; $\hat{\mathcal{B}}(B, X)=\hat{b}(B, 1, B, X)$.

3. Markets must clear. In particular, $\hat{\mathcal{Q}}(B, X)$ and $\hat{\mathcal{Q}}^{c}(B, X)$ are such that $\hat{s}(B, 1, B, X)=1$.

Given the definition of the equilibrium, notice that the equilibrium level of bonds can be characterized by a simple function of the aggregate state variables, $B^{\prime}=\hat{\mathcal{B}}(B, X)$, which together with the resource constraint defines consumption as a function of aggregate state variables, $\hat{\mathcal{C}}(B, X)$. 


\section{Social planner's recursive problem}

We consider a social planner that lacks commitment and that can only choose aggregate bond holdings for households but is still subject to the borrowing constraint. Following Klein et al. (2005), in order to solve for the time consistent policy, we focus on Markov stationary policy rules that only depend on the current state of the economy. In particular, they only depend on the aggregate state of the economy, $(B, X)$. We solve for the constrained efficient allocation following the three steps described in Klein et al. (2005): (i) We first define a recursive competitive equilibrium for arbitrary policy rules; (ii) we then proceed to define a constrained-efficient allocation for arbitrary policy rules of future planners; and (iii) we define the constrained efficient allocation for the case in which such policies are time consistent, that is, we solve for the fixed point of the game being played by successive planners. In this problem, the social planner makes the borrowing decisions for the households, so the planner is the one facing the collateral constraint. Households are allowed to trade stocks of the tree freely without government intervention.

Let us consider a planner who chooses an arbitrary sequence of state-contingent lump-sum transfers, $\left\{T_{t}\right\}_{t=0}^{\infty}$. Given this sequence of transfers, we can write down the Bellman equation for the household's problem as follows:

$$
V^{A}(s, T, X)=\max _{c, s^{\prime}}\left\{u(c)+\beta \mathbb{E}\left[V^{A}\left(s^{\prime}, T^{\prime}, X^{\prime}\right) \mid X\right]\right\}
$$

subject to

$$
c+\mathcal{Q}^{A}(T, X) s^{\prime}=\left[\mathcal{Q}^{A}(T, X)+d(X)\right] s+T .
$$

When solving this problem, the household takes the pricing function, $\mathcal{Q}^{A}(T, X)$, and the sequence of transfers as given. The solution to this problem is characterized by a policy rule for stock holdings, $s^{A}(s, T, X)$, such that Euler equation for stock holdings holds,

$$
\mathcal{Q}^{A}(T, X)=\frac{\beta \mathbb{E}\left[u^{\prime}\left(c^{\prime}\right)\left(\mathcal{Q}^{A}\left(T^{\prime}, X^{\prime}\right)+d\left(X^{\prime}\right)\right) \mid X\right]}{u^{\prime}(c)},
$$

where

$$
c+\mathcal{Q}^{A}(T, X) s^{A}(s, T, X)=\left[\mathcal{Q}^{A}(T, X)+d(X)\right] s+T .
$$

Notice that the resource constraint of the economy implies that $T=B-\frac{B^{\prime}}{R(X)}$. Hence, given $B$, the planner actually chooses $T$ by choosing $B^{\prime}$. Therefore, we can rewrite the planner's policy rule as one that dictates $B^{\prime}$ as a function of the current aggregate state, $(B, X)$. Call 
this policy rule $\Psi(B, X)$, and define the following functions:

$$
\begin{aligned}
\mathcal{Q}(B, X) & \equiv \mathcal{Q}^{A}\left(B-\frac{\Psi(B, X)}{R(X)}, X\right), \\
s(s, B, X) & \equiv s^{A}\left(s, B-\frac{\Psi(B, X)}{R(X)}, X\right), \text { and } \\
V(s, B, X) & \equiv V^{A}\left(s, B-\frac{\Psi(B, X)}{R(X)}, X\right) .
\end{aligned}
$$

Hence, we can rewrite the optimality conditions for the household's problem as follows:

$$
\mathcal{Q}(B, X)=\frac{\beta \mathbb{E}\left[u^{\prime}\left(c^{\prime}\right)\left(\mathcal{Q}\left(B^{\prime}, X^{\prime}\right)+d\left(X^{\prime}\right)\right) \mid X\right]}{u^{\prime}(c)}
$$

where

$$
c+\mathcal{Q}(B, X) \hat{s}(s, T, X)=[\mathcal{Q}(B, X)+d(X)] s+B-\frac{\Psi(B, X)}{R(X)}
$$

Definition A recursive competitive equilibrium for an arbitrary policy rule $\Psi(B, X)$ consists of a pricing function, $\hat{\mathcal{Q}}(B, X)$, and decision rules for households, $\hat{s}(s, B, X)$, with associated value function $\hat{V}(s, B, X)$, such that:

1. Given $\Psi(B, X)$ and $\hat{\mathcal{Q}}(B, X)$, households' decision rules $\hat{s}(s, B, X)$ and the associated value function $\hat{V}(s, B, X)$ solve the recursive problem of the household.

2. Markets clear: $\hat{\mathcal{Q}}(B, X)$ is such that $\hat{s}(s, B, X)=1$ and the resource constraint holds: $c+\frac{B^{\prime}}{R(X)}=B+d(X)$, where $B^{\prime}=\Psi(B, X)$.

Therefore, in such an equilibrium, we have that the following set of equations must be satisfied:

$$
\begin{aligned}
\hat{\mathcal{Q}}(B, X) & =\frac{\beta \mathbb{E}\left[u^{\prime}\left(B^{\prime}+d(X)-\frac{B^{\prime \prime}}{R(X)}\right)\left[\hat{\mathcal{Q}}\left(B^{\prime}, X^{\prime}\right)+d\left(X^{\prime}\right)\right] \mid X\right]}{u^{\prime}\left(B+d(X)-\frac{B^{\prime}}{R(X)}\right)}, \\
B^{\prime} & =\Psi(B, X) \text { and } B^{\prime \prime}=\Psi\left(\Psi(B, X), X^{\prime}\right) .
\end{aligned}
$$

Given that the planner we consider can only affect the allocation of bond holdings but cannot directly intervene in the markets for stocks, the pricing condition for $\hat{\mathcal{Q}}(B, X)$ has to hold in a constrained efficient allocation; in particular, this condition defines the price at which lenders value collateral in the current period borrowing constraint. Taking into account this kind of implementability constraint for the planner, we can now define the problem to be solved by a planner that takes as given the policy functions of future planners. Given future policy rules, $\Psi(B, X)$, associated pricing function $\hat{\mathcal{Q}}(B, X)$, and consumption rule $\mathcal{C}(B, X)$, the current 
planner chooses current consumption, $c$, and future bond holdings, $B^{\prime}$, to solve the following Bellman equation:

$$
W(B, X)=\max _{c, B^{\prime}}\left\{u(c)+\beta \mathbb{E}\left[W\left(B^{\prime}, X^{\prime}\right) \mid X\right]\right\}
$$

subject to

$$
\begin{aligned}
c+\frac{B^{\prime}}{R(X)} & =d(X)+B, \\
-\frac{B^{\prime}}{R(X)} & \leq \kappa \tilde{\mathcal{Q}}\left(c, B^{\prime}, X\right),
\end{aligned}
$$

where

$$
\tilde{\mathcal{Q}}\left(c, B^{\prime}, X\right)=\frac{\beta \mathbb{E}\left[u^{\prime}\left(\mathcal{C}\left(B^{\prime}, X^{\prime}\right)\right)\left(\mathcal{Q}\left(B^{\prime}, X^{\prime}\right)+d\left(X^{\prime}\right)\right) \mid X\right]}{u^{\prime}(c)},
$$

and $\mathcal{C}\left(B^{\prime}, X^{\prime}\right)=d\left(X^{\prime}\right)+B^{\prime}-\frac{\Psi\left(B^{\prime}, X^{\prime}\right)}{R\left(X^{\prime}\right)}$.

Definition A constrained efficient allocation given a policy rule for future planners $\Psi(B, X)$, with associated pricing function $\hat{\mathcal{Q}}(B, X)$ and consumption rule $\mathcal{C}(B, X)$, consists of an optimal policy rule, $\hat{\Psi}(B, X)$, such that given functions $\Psi(B, X), \hat{\mathcal{Q}}(B, X)$ and $\mathcal{C}(B, X)$, the current policy rule $B^{\prime}=\hat{\Psi}(B, X)$ and associated value function $\hat{W}(B, X)$ solve the recursive problem of the current planner.

Let us define the following function,

$$
\overline{\mathcal{Q}}\left(B, B^{\prime}, X\right)=\beta \mathbb{E}\left[\frac{u^{\prime}\left(B^{\prime}+d\left(X^{\prime}\right)-\frac{\Psi\left(B^{\prime}, X^{\prime}\right)}{R\left(X^{\prime}\right)}\right)\left[\hat{\mathcal{Q}}\left(B^{\prime}, X^{\prime}\right)+d\left(X^{\prime}\right)\right]}{u^{\prime}\left(d(X)+B-\frac{B^{\prime}}{R(X)}\right)} \mid X\right] .
$$

Then, $\hat{\Psi}(B, X)$ has to be such that the generalized Euler equation holds:

$$
\begin{aligned}
u^{\prime}(\hat{\mathcal{C}}(B, X)) & -\hat{\mu}(B, X)[1+\kappa R(X) \xi(B, X)] \\
& =R(X) \beta \mathbb{E}\left[u^{\prime}\left(\mathcal{C}\left(B^{\prime}, X^{\prime}\right)\right)+\kappa \hat{\mu}\left(B^{\prime}, X^{\prime}\right) \psi\left(B^{\prime}, X^{\prime}\right) \mid X\right],
\end{aligned}
$$

where $\psi(B, X)=\frac{\partial \overline{\mathcal{Q}}(B, \Psi(B, X), X)}{\partial B}, \xi(B, X)=\frac{\partial \overline{\mathcal{Q}}(B, \Psi(B, X), X)}{\partial B^{\prime}}$, and $\hat{\mathcal{C}}(B, X)=B+d(X)-\frac{\hat{\Psi}(B, X)}{R(X)}$. The multiplier on the collateral constraint is given by

$$
\begin{aligned}
\hat{\mu}(B, X) & =\max \left\{0, \frac{1}{1+\kappa R(X) \xi(B, X)}\left[u^{\prime}\left(B+d(X)-\frac{\hat{\Psi}(B, X)}{R(X)}\right)\right.\right. \\
& \left.\left.-\beta R(X) \mathbb{E}\left[u^{\prime}\left(\mathcal{C}\left(B^{\prime}, X^{\prime}\right)\right)+\kappa \mu\left(B^{\prime}, X^{\prime}\right) \psi\left(B^{\prime}, X^{\prime}\right) \mid X\right]\right]\right\},
\end{aligned}
$$


where $\hat{\Psi}(B, X)=-R(X) \kappa \overline{\mathcal{Q}}(B, \Psi(B, X), X)$. After this characterization of the allocation, we can now define a recursive constrained efficient allocation as follows.

Definition The recursive constrained efficient allocation consists of functions $\Psi(B, X), \hat{\mathcal{Q}}(B, X)$, $\mathcal{C}(B, X)$, and $\hat{\Psi}(B, X)$ with associated value function, $\hat{W}(B, X)$, such that

1. $\hat{\mathcal{Q}}(B, X), \mathcal{C}(B, X), \hat{\Psi}(B, X)$, and the associated value function $\hat{W}(B, X)$, constitute a constrained efficient allocation, given a policy rule for future planners, $\Psi(B, X)$.

2. The planner's plans are time-consistent: $\hat{\Psi}(B, X)=\Psi(B, X)$ and $\overline{\mathcal{Q}}(B, \hat{\Psi}(B, X), X)=\hat{\mathcal{Q}}(B, X)$.

\section{C.1 Derivation of equation (18)}

Non-binding current collateral constraint: $\mu(B, X)=0 \quad$ Given our definition of $\overline{\mathcal{Q}}\left(B, B^{\prime}, X\right)$, notice that

$$
\begin{aligned}
\frac{\partial \overline{\mathcal{Q}}\left(B, B^{\prime}, X\right)}{\partial B} & =\beta \mathbb{E}\left\{-\frac{u^{\prime}\left(\mathcal{C}\left(B^{\prime}, X^{\prime}\right)\right)\left(\hat{\mathcal{Q}}\left(B^{\prime}, X^{\prime}\right)+d\left(X^{\prime}\right)\right)}{u^{\prime}(c)} \frac{u^{\prime \prime}(c)}{u^{\prime}(c)}\right\} \\
& =-\frac{u^{\prime \prime}(c)}{u^{\prime}(c)} \overline{\mathcal{Q}}\left(B, B^{\prime}, X\right),
\end{aligned}
$$

which implies that

$$
\psi(B, X)=-\frac{u^{\prime \prime}(\mathcal{C}(B, X))}{u^{\prime}(\mathcal{C}(B, X))} \hat{\mathcal{Q}}(B, X) .
$$

Therefore, when $\mu(B, X)=0$, condition (20) becomes an Euler equation with one wedge, $\mu$,

$$
u^{\prime}(\hat{\mathcal{C}}(B, X))=R(X) \beta \mathbb{E}\left[u^{\prime}\left(\mathcal{C}\left(B^{\prime}, X^{\prime}\right)\right)-\kappa \hat{\mu}\left(B^{\prime}, X^{\prime}\right) \frac{u^{\prime \prime}\left(\mathcal{C}\left(B^{\prime}, X^{\prime}\right)\right)}{u^{\prime}\left(\mathcal{C}\left(B^{\prime}, X^{\prime}\right)\right)} \hat{\mathcal{Q}}\left(B^{\prime}, X^{\prime}\right) \mid X\right],
$$

precisely as in equation (16).

Binding current collateral constraint: $\mu(B, X)>0$ First note that the current planner has to choose $B^{\prime}$ subject to the collateral constraint

$$
\frac{B^{\prime}}{R(X)}+\kappa \overline{\mathcal{Q}}\left(B, B^{\prime}, X\right) \geq 0
$$

Following Jeanne and Korinek (2010), note that if the left-hand side of the previous inequality is strictly increasing in $B^{\prime}$, then, for any given $B$, there is a unique $B^{\prime}$ such that this equation holds with equality. Call this $\bar{B}^{\prime}$. Hence, for every $(B, X)$, there exists a $\bar{B}^{\prime}$ such that 
$\frac{\bar{B}^{\prime}}{R(X)}+\kappa \overline{\mathcal{Q}}\left(B, \bar{B}^{\prime}, X\right)=0$. Hence, when the collateral constraint is binding, the optimal policy rule by the current planner must be such that $\hat{\Psi}(B, X)=\bar{B}^{\prime}$, and we obtain that $\frac{\hat{\Psi}(B, X)}{R(X)}+\kappa \overline{\mathcal{Q}}(B, \hat{\Psi}(B, X), X)=0$. Hence, this policy rule is unique, implying that $\xi(B, X)=0 .{ }^{52}$

Now, notice that the left-hand side of (21) is strictly increasing whenever

$$
\frac{\partial}{\partial B^{\prime}}\left(\frac{B^{\prime}}{R(X)}+\kappa \overline{\mathcal{Q}}\left(B, B^{\prime}, X\right)\right)=\frac{1}{R(X)}+\kappa \xi(B, X)>0
$$

which is precisely our assumption in footnote $32,1+\kappa R(X) \xi(B, X)>0$.

In equilibrium, $\xi(B, X)<0$, therefore we expect this condition to hold whenever $\kappa$ is a small number. ${ }^{53}$ Given the definition of $\bar{Q}\left(B, B^{\prime}, X\right)$, notice that

$$
\frac{\partial \overline{\mathcal{Q}}\left(B, B^{\prime}, X\right)}{\partial B^{\prime}}=\frac{\beta \mathbb{E}\left[\Omega\left(B, B^{\prime}, X\right)\right]}{u^{\prime}(c)}+\frac{u^{\prime \prime}(c)}{u^{\prime}(c)} \frac{\overline{\mathcal{Q}}\left(B, B^{\prime}, X\right)}{R(X)}
$$

where

$$
\Omega\left(B, B^{\prime}, X\right)=u^{\prime \prime}\left(\mathcal{C}\left(B^{\prime}, X^{\prime}\right)\right) \frac{\partial \mathcal{C}\left(B^{\prime}, X^{\prime}\right)}{\partial B}\left[\mathcal{Q}\left(B^{\prime}, X^{\prime}\right)+d\left(X^{\prime}\right)\right]+u^{\prime}\left(\mathcal{C}\left(B^{\prime}, X^{\prime}\right)\right) \frac{\partial \mathcal{Q}\left(B^{\prime}, X^{\prime}\right)}{\partial B}
$$

This last expression shows how the current planner takes into account how decisions affect future planners' actions by changing $B^{\prime}$.

\section{Numerical solution method}

\section{D.1 Competitive equilibrium}

Let us denote by $B$ the aggregate equilibrium savings of the economy, and by $X=\left(z, r, \sigma^{r}\right)$ the realization of exogenous shocks. We wish to find functions $\mathcal{B}(B, X), \mathcal{C}(B, X), \mathcal{Q}(B, X)$,

\footnotetext{
${ }^{52}$ Another way to show this is by substituting the pricing function $\mathcal{Q}$ for the actual values $\bar{q}=\overline{\mathcal{Q}}\left(B, \bar{B}^{\prime}, X\right)$, which would imply that the constraint no longer depends on $B^{\prime}$.

${ }^{53}$ Notice that when $\kappa$ is small enough, the term $\kappa \mu\left(B^{\prime}, X^{\prime}\right) \psi\left(B^{\prime}, X^{\prime}\right)$ also becomes very small and $\hat{\Psi}(B, X)$ is unique in the case in which $\mu(B, X)=0$.
} 
$\mathcal{Q}^{c}(B, X)$, and $\mu(B, X)$ that satisfy

$$
\begin{aligned}
u^{\prime}(\mathcal{C}(B, X)) & =\beta R(X) \mathbb{E}\left[u^{\prime}\left(\mathcal{C}\left(\mathcal{B}(B, X), X^{\prime}\right)\right) \mid X\right]+\mu(B, X), \\
\mathcal{C}(B, X)+\frac{\mathcal{B}(B, X)}{R(X)} & =d(X)+B \\
-\frac{\mathcal{B}(B, X)}{R(X)} & \leq \kappa \mathcal{Q}(B, X), \\
\mathcal{Q}^{c}(B, X) & =\beta \mathbb{E}\left[\frac{u^{\prime}\left(\mathcal{C}\left(\mathcal{B}(B, X), X^{\prime}\right)\right)\left[\mathcal{Q}\left(\mathcal{B}(B, X), X^{\prime}\right)+d\left(X^{\prime}\right)\right]}{u^{\prime}(\mathcal{C}(B, X))-\kappa \mu(B, X)} \mid X\right], \\
\mathcal{Q}(B, X) & =\left(1+\frac{\kappa \mu(B, X)}{u^{\prime}(\mathcal{C}(B, X))}\right) \mathcal{Q}^{c}(B, X) .
\end{aligned}
$$

We extend the endogenous grid method (EGM) of Carroll (2006) to our framework where there is a borrowing constraint that binds occasionally:

1. For each $\sigma^{r} \in\left\{\sigma_{L}^{r}, \sigma_{H}^{r}\right\} \equiv \mathcal{S}$, calculate the transition matrix for a discrete approximation to the $\operatorname{VAR}(1)$ process of $(z, r)$ over $\mathcal{Z} \times \mathcal{R}$, with $\mathcal{Z}=\left\{z_{1}, \ldots, z_{N z}\right\}$ and $\mathcal{R}=\left\{r_{1}, \ldots, r_{N z}\right\}$.

2. Generate a grid $\overline{\mathcal{B}}=\left\{b_{1}, b_{2}, \ldots, b_{N}\right\}$, and an extended grid

$$
\overline{\overline{\mathcal{B}}}=\overline{\mathcal{B}} \cup\left\{b_{N+1}, b_{N+2}, \ldots, b_{N+M}\right\}
$$

where $b_{N+M}$ is chosen such that the resulting $\max _{X} \mathcal{B}\left(b_{N}, X\right) \leq b_{N+M}$ (to be verified in the end).

3. Guess functions $\mathcal{C}_{1}(B, X), \mathcal{Q}_{1}(B, X)$ and $\mathcal{Q}_{1}^{c}(B, X)$, for every $(B, X) \in \overline{\overline{\mathcal{B}}} \times \mathcal{Z} \times \mathcal{R} \times \mathcal{S}$. The initial guess we use is

$$
\begin{aligned}
& \mathcal{C}_{1}(B, X)=d(X)+B\left(1-\frac{1}{R(X)}\right), \\
& \mathcal{Q}_{1}(B, X)=\frac{\beta}{1-\beta} d(X),
\end{aligned}
$$

and $\mathcal{Q}_{1}^{c}(B, X)=\mathcal{Q}_{1}(B, X)$, which corresponds to the assumption that $\mathcal{B}(B, X)=B$, $z^{\prime}=z$ and $r^{\prime}=r$ for all $(B, X)$.

4. Set $\mathcal{C}_{0}(B, X)=\mathcal{C}_{1}(B, X), \mathcal{Q}_{0}(B, X)=\mathcal{Q}_{1}(B, X)$ and $\mathcal{Q}_{0}^{c}(B, X)=\mathcal{Q}_{1}^{c}(B, X)$ for each $(B, X) \in \overline{\bar{B}} \times \mathcal{Z} \times \mathcal{R} \times \mathcal{S}$. 
5. Assume that (26) does not bind. Use (24) and (25) to calculate

$$
\begin{aligned}
& \hat{\mathcal{C}}\left(B^{\prime}, X\right)=u^{\prime-1}\left(\beta R(X) \mathbb{E}\left[u^{\prime}\left(\mathcal{C}_{0}\left(B^{\prime}, X^{\prime}\right)\right) \mid X\right]\right), \\
& \hat{\mathcal{B}}\left(B^{\prime}, X\right)=\hat{\mathcal{C}}\left(B^{\prime}, X\right)+\frac{B^{\prime}}{R(X)}-d(X) .
\end{aligned}
$$

Notice that $\hat{\mathcal{B}}$ is the level of contemporaneous savings that yield an optimal savings decision $B^{\prime}$ when the realization of shocks is $X$ and the borrowing constraint does not bind.

6. For each $X$, let us denote by $\overline{\hat{\mathcal{B}}}(X)$ the endogenous grid of points generated by $\hat{\mathcal{B}}\left(B^{\prime}, X\right)$. For every $X$, interpolate $B^{\prime}$ from $\hat{\mathcal{B}}\left(B^{\prime}, X\right)$ to $\overline{\mathcal{B}}$, and denote the resulting function $\check{B}(B, X)$.

7. Calculate $\tilde{\mathcal{B}}(B, X)=\max \left\{\check{B}(B, X),-\kappa R(X) \mathcal{Q}_{0}^{c}(B, X)\right\}$, and the corresponding consumption:

$$
\tilde{\mathcal{C}}(B, X)=d(X)+B-\frac{\tilde{\mathcal{B}}^{\prime}(B, X)}{R(X)} .
$$

8. Find $\mathcal{B}^{*}(B, X)=\min \{B \in \overline{\overline{\mathcal{B}}}: B \geq \tilde{\mathcal{B}}(B, X)\}$. Using (24), (27) and (28), find

$$
\begin{aligned}
\tilde{\mu}(B, X) & =u^{\prime}(\tilde{\mathcal{C}}(B, X))-\beta R(X) \mathbb{E}\left[u^{\prime}\left(\mathcal{C}_{0}\left(\mathcal{B}^{*}(B, X), X^{\prime}\right)\right) \mid X\right] \\
\tilde{\mathcal{Q}}^{c}(B, X) & =\beta \mathbb{E}\left[\frac{u^{\prime}\left(\mathcal{C}_{0}\left(\mathcal{B}^{*}(B, X), X^{\prime}\right)\right)\left[\mathcal{Q}_{0}\left(\mathcal{B}^{*}(B, X), X^{\prime}\right)+d\left(X^{\prime}\right)\right]}{u^{\prime}(\tilde{\mathcal{C}}(B, X))-\kappa \tilde{\mu}(B, X)} \mid X\right], \\
\tilde{\mathcal{Q}}(B, X) & =\left(1+\frac{\kappa \tilde{\mu}(B, X)}{u^{\prime}(\tilde{\mathcal{C}}(B, X))}\right) \tilde{\mathcal{Q}}^{c}(B, X) .
\end{aligned}
$$

9. For every $(B, X) \in \overline{\mathcal{B}} \times \mathcal{Z} \times \mathcal{R} \times \mathcal{S}$, update

$$
\begin{aligned}
& \mathcal{C}_{1}(B, X)=\alpha \tilde{\mathcal{C}}(B, X)+(1-\alpha) \mathcal{C}_{0}(B, X) \\
& \mathcal{Q}_{1}(B, X)=\alpha \tilde{\mathcal{Q}}(B, X)+(1-\alpha) \mathcal{Q}_{0}(B, X) \\
& \mathcal{Q}_{1}^{c}(B, X)=\alpha \tilde{\mathcal{Q}}^{c}(B, X)+(1-\alpha) \mathcal{Q}_{0}^{c}(B, X)
\end{aligned}
$$

for some $\alpha \in(0,1]$. For $B \in \overline{\overline{\mathcal{B}}} \overline{\mathcal{B}}$, set $\mathcal{C}_{1}(B, X)=\mathcal{C}_{1}\left(b_{N}, X\right), \mathcal{Q}_{1}(B, X)=\mathcal{Q}_{1}\left(b_{N}, X\right)$ and $\mathcal{Q}_{1}^{c}(B, X)=\mathcal{Q}_{1}^{c}\left(b_{N}, X\right)$.

10. Repeat steps 4-9 until convergence. 


\section{D.2 Constrained efficient allocation}

The constrained efficient allocation satisfies

$$
\begin{aligned}
u^{\prime}(\mathcal{C}(B, X)) & -\mu(B, X)[1+\kappa R(X) \xi(B, X)] \\
& =R(X) \beta \mathbb{E}\left[u^{\prime}\left(\mathcal{C}\left(B^{\prime}, X^{\prime}\right)\right)+\kappa \mu\left(B^{\prime}, X^{\prime}\right) \psi\left(B^{\prime}, X^{\prime}\right) \mid X\right] \\
\mathcal{Q}(B, X) & =\beta \mathbb{E}\left[\frac{u^{\prime}\left(\mathcal{C}\left(\mathcal{B}(B, X), X^{\prime}\right)\left[\mathcal{Q}\left(\mathcal{B}(B, X), X^{\prime}\right)+d\left(X^{\prime}\right)\right]\right.}{u^{\prime}(\mathcal{C}(B, X))-\kappa \mu(B, X)} \mid X\right],
\end{aligned}
$$

together with (25) and (26). Some steps of the EGM algorithm change with respect to the solution of the competitive equilibrium:

3. Guess functions $\mathcal{C}_{1}(B, X), \mathcal{Q}_{1}(B, X)$ and $\mu_{1}(B, X)$ for every $(B, X) \in \overline{\mathcal{B}} \times \mathcal{Z} \times \mathcal{R} \times \mathcal{S}$. The initial guess we use is: $\mu_{1}(B, X)=0$.

4. Set $\mathcal{C}_{0}(B, X)=\mathcal{C}_{1}(B, X), \mathcal{Q}_{0}(B, X)=\mathcal{Q}_{1}(B, X)$ and $\mu_{0}(B, X)=\mu_{1}(B, X)$ for each $(B, X) \in \overline{\overline{\mathcal{B}}} \times \mathcal{Z} \times \mathcal{R} \times \mathcal{S}$.

Calculate:

$$
\psi(B, X)=-\frac{u^{\prime \prime}\left(\mathcal{C}_{0}(B, X)\right)}{u^{\prime}\left(\mathcal{C}_{0}(B, X)\right)} \mathcal{Q}_{0}(B, X) .
$$

Use the numerical derivatives of $C_{0}$ and $Q_{0}$ with respect to $B$ to calculate $\xi(B, X)$ using equation (23) of Appendix C.

5. Assume that (26) does not bind. Use (29) and (25) to calculate:

$$
\begin{aligned}
& \hat{\mathcal{C}}\left(B^{\prime}, X\right)=u^{\prime-1}\left(\beta R(X) \mathbb{E}\left[u^{\prime}\left(\mathcal{C}_{0}\left(B^{\prime}, X^{\prime}\right)\right)+\kappa \mu_{0}\left(B^{\prime}, X^{\prime}\right) \psi\left(B^{\prime}, X^{\prime}\right) \mid X\right]\right), \\
& \hat{\mathcal{B}}\left(B^{\prime}, X\right)=\hat{\mathcal{C}}\left(B^{\prime}, X\right)+\frac{B^{\prime}}{R(X)}-d(X) .
\end{aligned}
$$

8. Find $\mathcal{B}^{*}(B, X)=\min \{B \in \overline{\overline{\mathcal{B}}}: B \geq \tilde{\mathcal{B}}(B, X)\}$. Using (29) and (30), find:

$$
\begin{aligned}
& \tilde{\mu}(B, X)=\frac{1}{1+\kappa R(X) \xi(B, X)}\left\{u^{\prime}(\tilde{\mathcal{C}}(B, X))\right. \\
& \left.-\beta R(X) \mathbb{E}\left[u^{\prime}\left(\mathcal{C}_{0}\left(\mathcal{B}^{*}(B, X), X^{\prime}\right)\right)+\kappa \mu_{0}\left(\mathcal{B}^{*}(B, X), X^{\prime}\right) \psi\left(\mathcal{B}^{*}(B, X), X^{\prime}\right) \mid X\right]\right\}, \\
& \tilde{\mathcal{Q}}(B, X)=\beta \mathbb{E}\left[\frac{u^{\prime}\left(\mathcal{C}_{0}\left(\mathcal{B}^{*}(B, X), X^{\prime}\right)\right)\left[\mathcal{Q}_{0}\left(\mathcal{B}^{*}(B, X), X^{\prime}\right)+d\left(X^{\prime}\right)\right]}{u^{\prime}(\tilde{\mathcal{C}}(B, X))-\kappa \tilde{\mu}(B, X)} \mid X\right],
\end{aligned}
$$


Figure 16: Savings rule: Different endowment levels

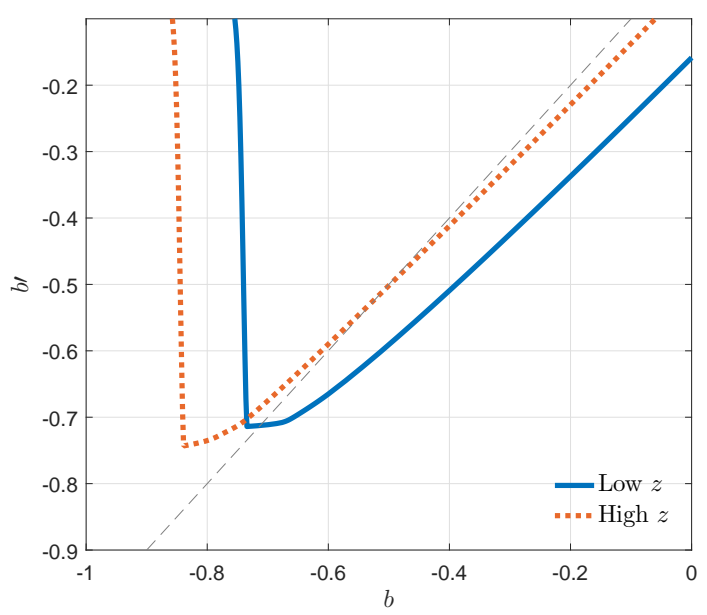

9. For every $(B, X) \in \overline{\mathcal{B}} \times \mathcal{Z} \times \mathcal{R} \times \mathcal{S}$, update:

$$
\begin{aligned}
& \mathcal{C}_{1}(B, X)=\alpha \tilde{\mathcal{C}}(B, X)+(1-\alpha) \mathcal{C}_{0}(B, X), \\
& \mathcal{Q}_{1}(B, X)=\alpha \tilde{\mathcal{Q}}(B, X)+(1-\alpha) \mathcal{Q}_{0}(B, X) \\
& \mu_{1}(B, X)=\alpha \tilde{\mu}(B, X)+(1-\alpha) \mu_{0}(B, X) .
\end{aligned}
$$

for some $\alpha \in(0,1]$. For $B \in \overline{\overline{\mathcal{B}}} \backslash \overline{\mathcal{B}}$, set $\mathcal{C}_{1}(B, X)=\mathcal{C}_{1}\left(b_{N}, X\right), \mathcal{Q}_{1}(B, X)=\mathcal{Q}_{1}\left(b_{N}, X\right)$ and $\mu_{1}(B, X)=\mu_{1}\left(b_{N}, X\right)$.

10. Repeat steps 4-9 until convergence.

\section{E Income Shocks}

In Figure 16, we compare the savings decision rule for two different levels of the contemporaneous endowment. When there is a high level of output in the period (orange dashed line), there tend to be greater savings from the households in the region where borrowing constraints do not bind. This effect occurs because households wish to smooth consumption across time, and because the process for the endowment is mean reverting, it is likely that in future periods there will be a lower output than in the present. However, because the endowment process is persistent, a high level of contemporaneous output predicts high levels of output in the near future, which in turn increases the value of the Lucas tree for the household. This rise causes an increase in the value of the collateral available in the economy, which raises the borrowing capacity of the households. Hence, the borrowing constraint starts binding at higher levels of debt, as the orange dashed line shows. 
Figure 17: Impulse-response functions
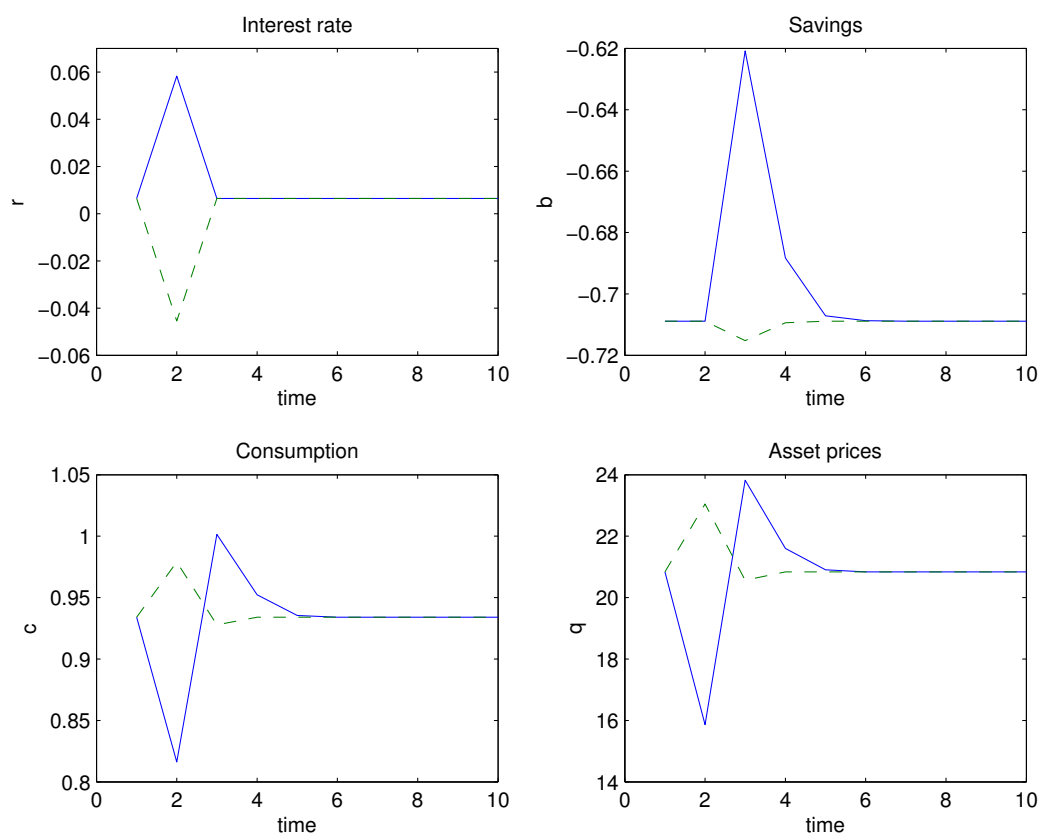

\section{F Asymmetric responses to interest rate shocks}

The nonlinear dynamics of the economy generate asymmetric responses to shocks in the level of interest rates. This feature plays a relevant role in allowing these shocks to generate dynamics around crises that are in line with empirical evidence. In Figure 17 we show our simulated impulse-responses around the steady state where the economy would remain if the level of output from the tree remained permanently constant at two standard deviations below its mean, the interest rate remained at $0.6 \%$, and the variance of the interest rate remained permanently at $6.6 \%$, that is, in the high volatility regime. We then give a $\pm 5.2 \%$ shock to the interest rate for one period and bring the interest rate to $0.6 \%$ thereafter. The idea of this exercise is to simulate a scenario in which changes in interest rates occur during turbulent times, similar to what many EMEs have experienced in distinct occasions. First, we explain the effects of the interest rate decrease on the rest of the economy (green dashed line). The immediate effect is an incentive for the households to consume in advance. Therefore, they increase their consumption $4.8 \%$ in the first period, without significant changes in the net savings of the economy. Asset prices show a $10.6 \%$ increase in the first period because the households are discounting future cash flows less, but they revert close to their long-run level in the following period.

In contrast, the economy responds very differently to an increase in the interest rate of the same magnitude. The immediate effect of the shock is a decline in asset prices, as shown in the last panel of the figure (blue solid line). The decline in the value of collateral causes the borrowing constraint to bind for a period, which forces a reduction in consumption in order to cut off the level of debt. As mentioned before, the feedback between deleveraging and the 
Figure 18: Histograms of leverage
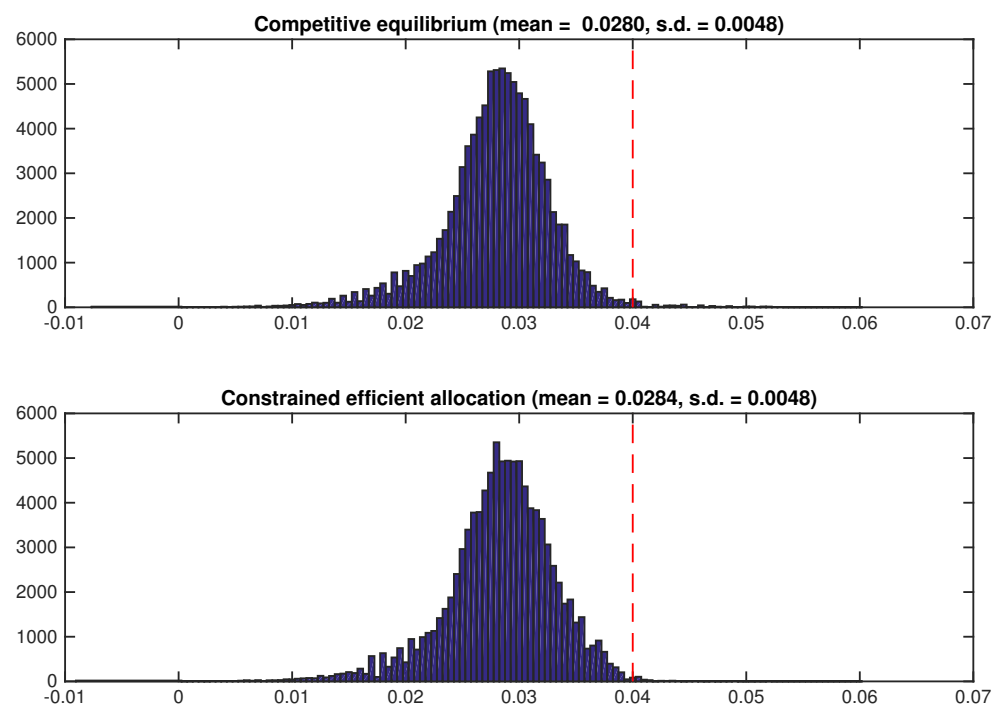

decline of asset prices amplifies the initial shock: Consumption initially falls $12.6 \%$, and asset prices drop 23.9\%. This response carries a sharp reduction in foreign debt: It goes from $70.9 \%$ of average output to $62.1 \%$ in just one period. In addition, as the graphs show, the sudden deleveraging has long-lasting effects: Given that there is a lower level of debt, asset prices remain high because there is a low probability of hitting the borrowing constraint again in the near future. Moreover, because the country has accumulated more savings, the household increases its consumption in the subsequent periods because it remains relatively impatient with respect to the rest of the world, until the stock of debt converges back to its long-run level. This exercise exemplifies the nonlinear and asymmetric dynamics of the model that arise from the presence of an occasionally binding borrowing constraint.

\section{G Ergodic state distribution}

Figure 18 shows the histograms of leverage for both the competitive equilibrium and the constrained efficient allocations. Here we define leverage as the discount value of debt divided by the market value of the Lucas tree, $-b_{t+1} / R_{t} q_{t}$. The red line marks the level of leverage where the borrowing constraint binds, given by $\kappa=0.04$ in our numerical example. Both histograms of leverage have a similar mean of around 0.028 and the same dispersion of 0.0048 .

\section{H Optimal macroprudential taxes and income shocks}

We now analyze how the planner's intervention responds to endowment shocks. The solid blue line in Figure 19 depicts the optimal tax on debt as a function of households' savings for a 
Figure 19: Optimal Tax

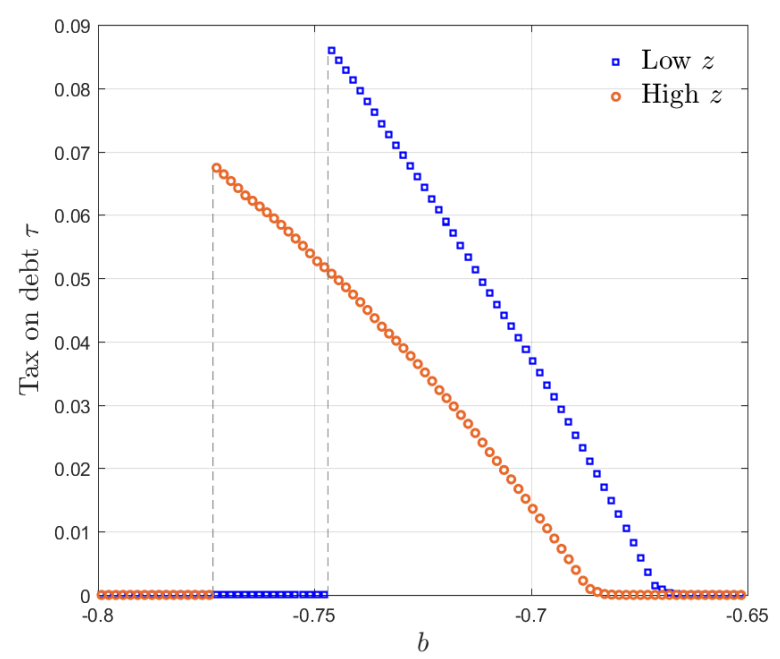

Figure 20: Decomposition of Optimal Tax
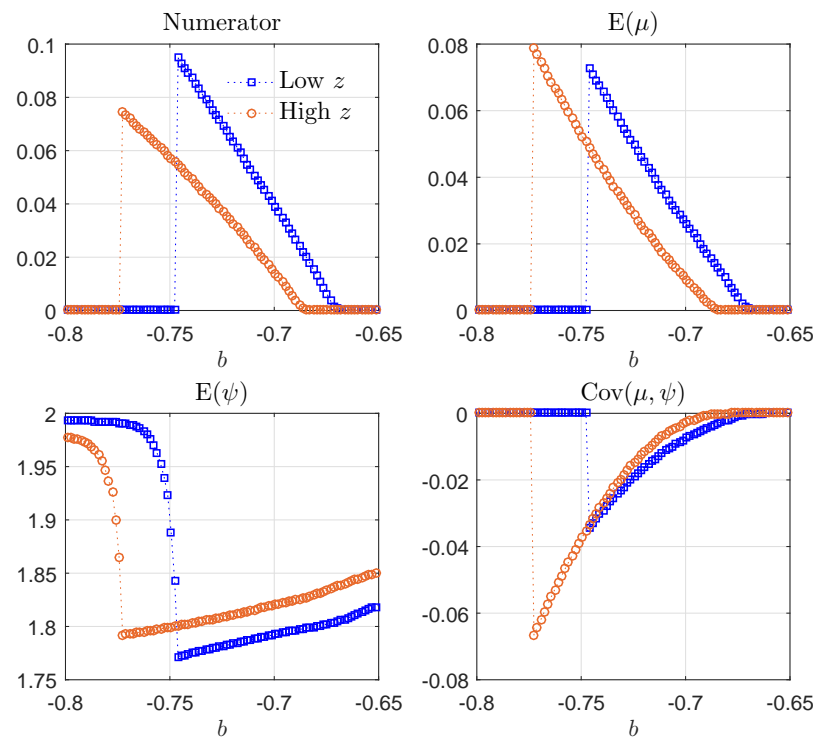

low realization of the endowment shock, $z$. In the region where borrowing is unconstrained independently of the endowment shock, the tax on debt is always higher for lower realizations of the endowment. This is explained by the fact that low levels of dividend reduce the value of the Lucas tree, which in turn decreases the value of collateral available and increases the probability of a binding borrowing constraint in the near future.

Figure 20 shows the decomposition of the numerator of $\tau(B, X)$ for two different levels of the endowment shock. The planner intervenes more after low endowment realizations because the collateral constraint now binds for lower levels of indebtedness. This issue arises because asset prices decline persistently given the persistence of the shock, which translates into a higher probability assigned to states in which the borrowing constraint binds in future periods and, therefore, an increase in the incidence of a future crisis, $\mathbb{E}_{t}\left[\mu_{t+1}\right]$. The effect of the severity of the externality, $\mathbb{E}_{t}\left[\psi_{t+1}\right]$, goes in the opposite direction precisely because asset prices drop persistently, but consumption does not drop as much. ${ }^{54}$ The covariance does not vary substantially across endowment levels precisely because it reassigns probabilities across crisis and no-crisis states, but the relationship between $\mu_{t+1}$ and $\psi_{t+1}$ across states does not change. We conclude that the effect of binding borrowing constraints, $\mathbb{E}_{t}\left[\mu_{t+1}\right]$, is the one driving the increase in the macroprudential tax after low endowment realizations.

\footnotetext{
${ }^{54}$ This effect can be seen in (16) and the fact that households borrow to smooth consumption, and is precisely the reason why changes in the numerator of the tax explain the changes in the tax as a whole.
} 